\title{
Tunnel Closure Calculations
}

\author{
Bill Moran \\ Armand Attia
}

A Report prepared for the

Munitions Division of the Armament Directorate at Eglin Air Force Base

July 1995

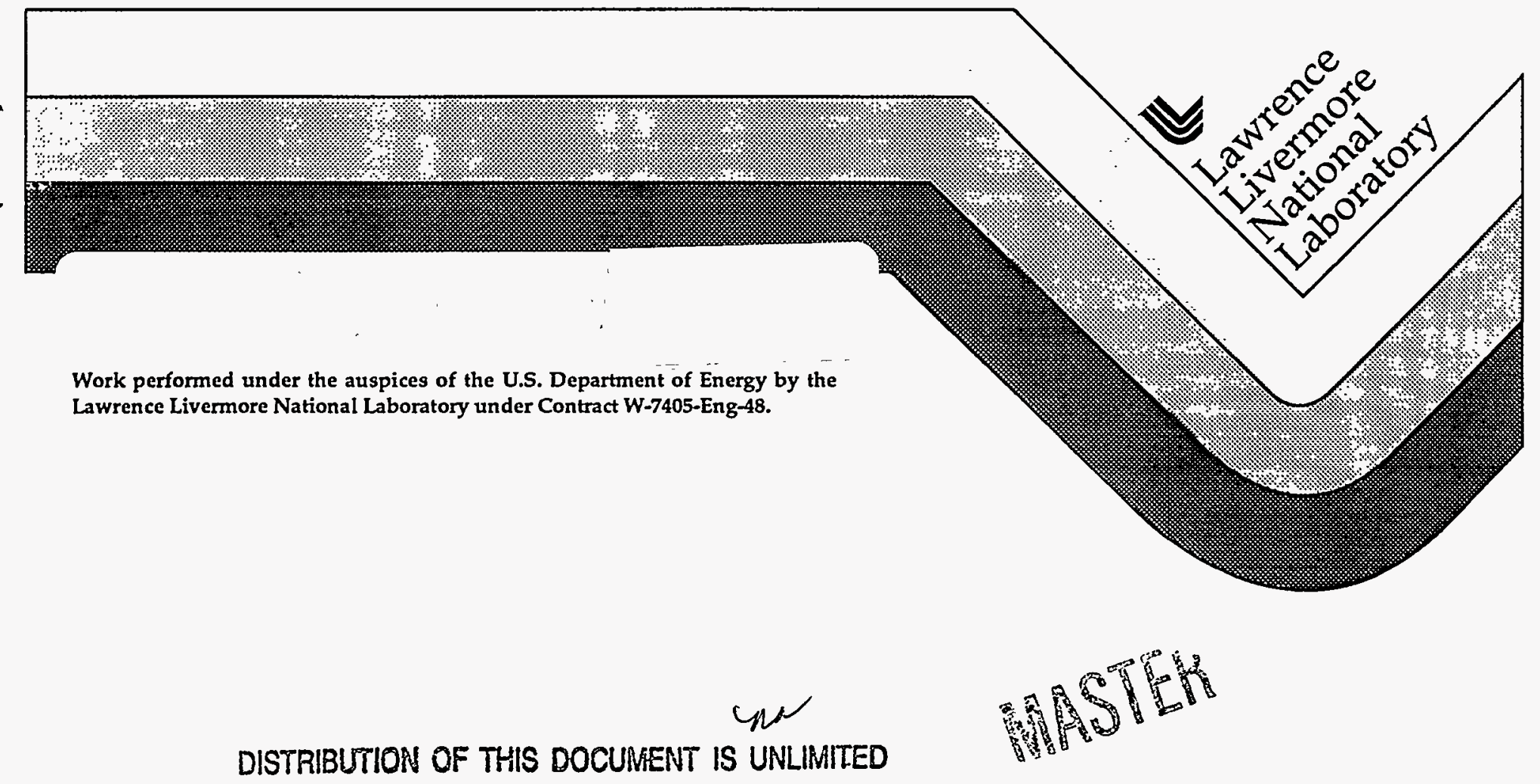




\section{DISCLAIMER}

This document was prepared as an account of work sponsored by an agency of the United States Government. Neither the United States Government nor the University of California nor any of their employees, makes any warranty, express or implied, or assumes any legal liability or responsibility for the accuracy, completeness, or usefulness of any information, apparatus, product, or process disclosed, or represents that its use would not infringe privately owned rights. Reference herein to any specific commercial product, process, or service by trade name, trademark, manufacturer, or otherwise, does not necesserily constitute or imply its endorsement, recommendation, or favoring by the United States Government or the University of California. The views and opinions of authors expressed herein do not necessarily state or reflect those of the United States Government or the University of California, and shall not be used for advertising or product endorsement purposes.

This report has been reproduced directly from the best available copy.

Available to DOE and DOE contractors from the Office of Scientific and Technical Information P.O. Box 62, Oak Ridge, TN 37831

Prices available from (615) 576-8401, FTS 626-8401

Available to the public from the National Technical Information Service

U.S. Department of Commerce 5285 Port Royal Rd. Springfield, VA 22161 


\section{DISCLAIMER}

Portions of this document may be illegible in electronic image products. Images are produced from the best available original document. 
Tunnel Closure Calculations

\author{
A Report prepared for the \\ Munitions Division of the Armament Directorate \\ at Eglin Air Force Base
}

Bill Moran and Armand Attia

\begin{abstract}
When a deeply penetrating munition explodes above the roof of a tunnel, the amount of rubble that falls inside the tunnel is primarily a function of three parameters: First the cube-root scaled distance from the center of the explosive to the roof of the tunnel. Second the material properties of the rock around the tunnel, and in particular the shear strength of that rock, its RQD (Rock Quality Designator), and the extent and orientation of joints. And third the ratio of the tunnel diameter to the standoff distance (distance between the center of explosive and the tunnel roof).
\end{abstract}

We have used CALE, a well-established 2-D hydrodynamic computer code, to calculate the amount of rubble that falls inside a tunnel as a function of standoff distance for two different tunnel diameters. In particular we calculated three of the tunnel collapse experiments conducted in an iron ore mine near Kirkeness, Norway in the summer of 1994. The failure model that we used in our calculations combines an equivalent plastic strain criterion with a maximum tensile strength criterion and can be calibrated for different rocks using cratering data as well as laboratory experiments. These calculations are intended to test and improve our understanding of both the Norway Experiments and the ACE (Array of conventional Explosive) phenomenology.

\title{
Introduction
}

An understanding of tunnel vulnerability to air-delivered munitions is required for weapon concept evaluation as well as for guiding data collection efforts. Furthermore, an accurate assessment of tunnel vulnerability would provide guidelines on how to engage these targets in the most efficient manner. Our desired goal is to provide code modules capable of predicting munitions effectiveness against a broad spectrum of tunnel targets. The munition effectiveness depends on the functional disruption it creates in a particular target. Some of the 
main mechanisms for creating such disruptions in an adit attack include adit blockage, debris impact, air blast, and in-structure shock. In this study, we focus only on the amount of rubble that falls inside the tunnel. Using a damage model, we predict the amount of rubble in three tunnel collapse experiments and describe how our calculations can be further extended.

\section{Tunnel Calculations using CALE}

We used the two-dimensional hydro-code CALE$^{1}$ (see slide 1) in all our simulations. Although there are many other 2 and 3-D hydrocodes $(2,3,4,5)$ available, we have chosen a $2-\mathrm{D}$ code in order to be able to perform a large number of calculations in a limited time and have chosen CALE because of its automatic rezoning and damage model capabilities. We modeled two perpendicular cross-sections of the tunnel and combined the results to obtain a total rubble volume as follows: First, consider a cross-section perpendicular to the tunnel length, as shown schematically on the top of slide 2. The initial location of the High Explosive (HE) is outlined with a narrow rectangle. For each vertical increment above the tunnel, calculate the consolidated width of the damaged material. Next, consider a crosssection parallel to the tunnel, as shown schematically at the bottom of slide 2 . For each vertical increment above the tunnel, calculate the consolidated length of the damaged material. Finally, calculate the volume by summing up the product of the length, the width and the vertical increment.

An estimate of the error that is made by modeling an inherentiy 3Dimensional problem using a 2-Dimensional code can be obtained in the limit of a very-large-diameter tunnel. In this case, the configuration is similar to that of a charge buried above a flat tunnel roof and the two damage cross-sections parallel and perpendicular to the tunnel become identical. If the rubble has the shape of a cone with a diameter $\mathrm{D}$ and height $\mathrm{H}$, then both cross-sections are triangular. The reconstruction of the rubble volume from the 2-D modeling would predict a pyramid having a height $\mathrm{H}$ and a square base with side D. Slide 3 illustrates this reconstruction and shows two perpendicular cuts in a conical-shaped rubble. The hatched strips represent the length and width of the damaged zone at a given distance above the tunnel. By comparing the volumes of the pyramid to that of the cone, we find that the 2-D approximation would overestimate the volume by a factor of $4 / \pi$ or about a $27 \%$ increase. 


\section{Failure model}

The failure model in the calculations is based on two main failure mechanisms for rocks: Failure in tension and failure in shear. Tensile failure, or spall, occurs when the most tensile principal stress exceeds some critical value. This mode of failure typically occurs near a free surface. Shear failure occurs when the equivalent plastic strain exceeds a critical value. This mode of failure typically occurs near the explosive. The model uses both criteria in advancing the damage variable from 0 (the unbroken state) to 1 (the completely broken state). Whenever the failure criteria are exceeded, the damage increases at a rate that is proportional to the elastic wave speed and inversely proportional to the characteristic distance across the zone. This simple rate law accounts for the fact that even if a zone breaks instantaneously, a certain amount of time must pass before this information can propagate to all corners of the zone. See slide 4 for the material properties and failure parameters used in the tunnel calculations. The model also accounts for the fact that once the material is broken, its ability to support shear stresses decreases. The yield strength of the broken material is smaller than that of the virgin rock; it increases linearly with confining pressure at a slope equal to the friction coefficient. The material properties of any computational zone are simply the linear combination of the zone's broken and unbroken properties.

The incorporation of the two failure mechanisms in a continuum code allows for prediction of important features such as spall and cratering. The continuum model however has limitations. Although it may accurately predict the amount of damaged material and its initial evolution, it cannot model the interactions of discrete blocks and thus cannot be expected to predict the lateral transposition of blocks or their final positions. A comparison between discrete and continuum modeling in cratering events is discussed by Killian et al6.

\section{The Norway tunnels}

A total of 3 adit and 2 portal tests were conducted in 3 different tunnels in the Bjoernevatn open pit mine during August 1994. The explosive material was tritonal and its weight was $525 \mathrm{lbs}(238 \mathrm{Kg})$. In table I below, we summarize the standoff distance from the center of the explosive (C.E.) to the roof of the tunnel. 


\begin{tabular}{|c|c|c|c|}
\hline Test \# & Site & Test type & Standoff $(\mathrm{m})$ \\
\hline 1 & Jerntoppen & Adit & 2.8 \\
\hline 3 & Sostervann A & Adit & 7.0 \\
\hline $4 \mathrm{~A}$ & Sostervann A & Portal & 3.5 \\
\hline 5 & Sostervann B & Adit & 3.7 \\
\hline $6 \mathrm{~B}$ & Sostervann B & Portal & 4.0 \\
\hline
\end{tabular}

There are two distinguishing characteristics of the Norway tunnels. First, the rock around the tunnels was water saturated and second the diameter of the tunnels was relatively large. Water saturation in rocks has been studied by Butkovich ${ }^{7}$ who demonstrated that at the same yield and depth of burial, vastly different ground motion is produced in rocks having different water contents. Broch 8 studied a variety of Norwegian strong rocks including gneiss, and suggested that the physical basis for the reduction in shear strength from water saturation is due to a reduction in the free surface energy $J$ and a reduction in the internal friction $\beta$. The effect of water saturation is threefold: reduce the shear strength of the rock, reduce its fracture toughness, and mitigate the anisotropy from joints. A reduction in shear strength produces larger amounts of rubble. A reduction in the fracture toughness produces a smaller average size of the rubble $(\mathrm{d} \propto$ $\mathrm{K}^{2 / 3}$ ). Mitigation of the anisotropy from joints means that modeling the rock as a homogeneous material using average properties for the rock mass is likely to predict reasonable estimates for the rubble volume. The detailed shape of the crater however, cannot be predicted without prior knowledge of the location and orientation of each joint in the rock. Such detailed knowledge is at best very difficult to obtain due to the fractal character 9 of fracture spacing in rocks. Even if such knowledge could be obtained, it is unlikely to be available in actual cases of interest. For these reasons, we did not model any joints in our continuum calculations but rather we let the state of stress in the rock determine the subsequent failure.

The second characteristic of the Norway tunnels is that the diameter of the tunnels was comparable to or larger than the standoff distances. The cross-sectional area of the tunnels was measured to be $22.3 \mathrm{~m}^{2}$ and the effective diameter was between 4.5 and $5 \mathrm{~m}$. For comparison, the 3 standoff distances for the adit experiments were $2.8,3.7$ and 7.0 $\mathrm{m}$. A large tunnel diameter relative to the standoff distance means that the free surface of the tunnel roof subtends a large solid angle. Since tensile failure occurs as a result of shock wave reflection from a 
free surface, a large tunnel diameter indicates larger regions with tensile failure.

The water saturation of the rock around the Norway tunnels, their relatively large size as well as the highly jointed nature of the rock (which we modeled using a low effective bulk modulus of $200 \mathrm{~kb}$ ) all indicate that the predicted rubble volumes from our calculations are larger than the predictions that would be obtained for similar experiments in smaller tunnels surrounded with dry competent rock. The characteristics and implications of the Norway tunnels and a plot of the effect of water saturation on the strength of Norwegian gneiss are outlined in slide 5 .

\section{Quantitative predictions}

In this section we present the main results of the parameter studies that we performed.

Effect of a non-spherical source: Our calculations indicate that the initial bomb configuration can be modeled as a spherical source as shown in slide 6 . There are both practical and numerical reasons for this investigation. From a practical point of view, it is important to evaluate the effect of initiation location on the peak pressure ahead of the bomb and to understand the effect of the bomb aspect ratio in order to optimize its effectiveness. From a numerical point of view, if we can model the bomb as a spherical source, fewer mesh points would be required for any given resolution and the calculational cost becomes more manageable particularly in 3-D. Slides 7,8 , and 9 compare the progression of pressure contours at $0.4,0.8$, and $1.2 \mathrm{~ms}$ for the bomb configuration and a spherized source. Slide 10 shows the pressure contours from the bomb configuration at $1.6 \mathrm{~ms}$. Slide 11 shows that the peak pressure beyond $3 \mathrm{~m}$ is nearly independent of initial configuration and slide 12 shows the equivalent plastic strain (a major component of damage) for both the bomb configuration and a spherical source with the same explosive mass. The calculations indicate that although the shape of the damaged zone differ in the two cases, the actual volume of the rubblized material is nearly identical. The calculations also show more damaged material ahead of the bomb than behind it as indicated by the solid colors in the bottom half compared with the streaked coloring on the top. 
Dependence on the scaled distance to the roof of the tunnel: Slide 13 shows the calculated final damage contours for the three adit experiments. The standoff distance $S$ and the volume $V$ of the rubblized material are indicated on each of the three cross-sections. To calculate the rubblized volume for each standoff distance, we carried out two 2-D calculations parallel and perpendicular to the tunnel using the material properties shown in slide 4 and the summation procedure outlined in slide 2 . We did not include a correction for a bulking factor in the volume calculations. That correction is small and is nearly canceled out by the fact that the 2-D approximation overestimates the volume compared with the more realistic 3-D calculations. For both standoff distances of $2.8 \mathrm{~m}$ and 3.7 $\mathrm{m}$, the calculations predict a blowout crater in which the shear failure near the explosive links up with tensile failure near the tunnel roof. For the largest standoff distance of $7.0 \mathrm{~m}$ however, there is a transition to a spall crater and a smaller amount of rubble volume.

In order to minimize the computational cost, all the calculations were carried out using a volume burn of a spherical charge having the same explosive weight as the actual bomb. The effect of this approximation is to produce a blunt more rounded crater than would be predicted from simulating the actual bomb configuration. This approximation however has little effect on the prediction of the rubblized material's volume as can be seen from the equivalent plastic strain contours in slide 12.

For the case where the standoff distance is $2.8 \mathrm{~m}$, slide 14 shows the arrival of the shock front to the tunnel roof and its reflection off the free surface. The peak pressure when the shock hits the tunnel roof is slightly over $1 \mathrm{~kb}$. The strong reflected wave, which reaches the explosive around $1.5 \mathrm{~ms}$, generates tensile failure that links up with the shear failure near the charge. Slide 15 shows the progression of damage at early times. At $0.7 \mathrm{~ms}$, all the damage is in the form of shear failure near the explosive. At $1 \mathrm{~ms}$, tensile failure appears in the tunnel roof and at $1.5 \mathrm{~ms}$, the shear and tensile failure begin to link up indicating a blowout crater.

Slide 16 shows the calculated beginning of the tunnel roof collapse and the damaged region at 7,14 , and $21 \mathrm{~ms}$. Notice the growth of the explosive cavity, the collapse of the roof and the near constant crosssectional area of the rubblized material that is shown in lavender. Slide 17 is a cross-section parallel to the tunnel showing the damaged region also at 7,14 , and $21 \mathrm{~ms}$. For the $2.8 \mathrm{~m}$ standoff distance, the 
calculated amount of damaged rock reaches its asymptotic value around $14 \mathrm{~ms}$.

In slide 18 we present an alternate way to differentiate between an eventual blowout and a spall crater. The contours of downward velocities for standoff distances of $2.8 \mathrm{~m}$ and $3.7 \mathrm{~m}$ show that even after the tunnel roof has moved about $1 \mathrm{~m}$, the material above the tunnel roof (shown in red) is moving faster than the material at the tunnel roof. This velocity gradient indicates that the material with the higher velocity will eventually push through the tunnel roof and result in a blowout crater. When the standoff distance was $7.0 \mathrm{~m}$ however, the peak downward velocity was at the tunnel roof suggesting that the material with the highest velocity will spall off the tunnel roof leaving competent material behind it.

Dependence on the diameter of the tunnel: To estimate the effect of the tunnel diameter, we calculated the amount of rubble that would fall in a small tunnel of cross-sectional area $\mathrm{A}=5.58 \mathrm{~m}^{2}$ and a diameter approximately half that of the Norway tunnels. Slide 19 shows that at a standoff distance of $2.8 \mathrm{~m}$, the calculated volume $\mathrm{V}$ of the rubble that would fall in the small tunnel is $74 \mathrm{~m}^{3}$, compared with $84 \mathrm{~m}^{3}$ for the Norway tunnel. At that small standoff, the damage contours indicate a blowout crater for both the small $\left(A=5.58 \mathrm{~m}^{2}\right)$ and large $\left(\mathrm{A}=22.3 \mathrm{~m}^{2}\right)$ tunnels.

When the standoff distance is $3.7 \mathrm{~m}$, slide 20 shows that there is a significant amount of partially fractured rock (shown as a blue island in a lavender lake of fully damaged rock) above the roof of the small tunnel. It is this partially fractured rock that indicates the near transition from a blowout to a spall crater as the standoff distance increases. The calculated rubble volume that would fall in the small tunnel at the $3.7 \mathrm{~m}$ standoff is $95 \mathrm{~m}^{3}$, compared with $126 \mathrm{~m}^{3}$ for the Norway tunnel.

Slide 21 shows the damage contours at a $7.0 \mathrm{~m}$ standoff for the small and large tunnels. Both calculations show a large region of undamaged rock between the explosive and the tunnel roof. The extent of the failed rock material is localized to two disconnected regions: shear failure near the explosive, and tensile failure near the tunnel roof, indicating a spall crater. The calculated rubble volume that would fall in the small tunnel at the $7.0 \mathrm{~m}$ standoff is $33 \mathrm{~m}^{3}$, compared with 59 $\mathrm{m}^{3}$ for the Norway tunnel. 
In Slide 22 we plot the calculated rubble volumes and crater depths as a function of standoff distance for both the small and large tunnels. The calculated crater depth is nearly independent of the tunnel crosssection $\mathrm{A}$, but the rubble volume at large standoff scales with the square root of $A$. This is because the amount of rock that fails in tension is nearly proportional to the portion of the tunnel roof surface area which is exposed to large tensile stresses. That portion of surface area however, scales with the tunnel diameter and thus with the square root of the tunnel cross-section A.

\section{Summary}

The main points in this report are summarized below:

- Using a 2-D hydro-code and modeling two perpendicular crosssections of the tunnels, we have developed a technique to predict the amount of rubble fallout.

- We used a damage model based on maximum equivalent plastic strain and maximum tensile stress and predicted the amount of rubble in 3 adit attack experiments. The results for water saturated fractured rock using $525 \mathrm{lbs}$ of tritonal are summarized in the Table II below:

Table II: Calculated crater depths and volumes

\begin{tabular}{|c|c|c|c|}
\hline Test \#* & Standoff $(\mathrm{m})$ & Depth $(\mathrm{m})$ & Volume $\left(\mathrm{m}^{3}\right)$ \\
\hline 1 & 2.8 & 4.9 & 84 \\
\hline 3 & 7.0 & 1.0 & 59 \\
\hline 5 & 3.7 & 5.8 & 126 \\
\hline 1S & 2.8 & 4.9 & 74 \\
\hline $3 S$ & 7.0 & 1.0 & 33 \\
\hline SS & 3.7 & 5.7 & 95 \\
\hline
\end{tabular}

*Tests designated with $\mathrm{S}$ are for small tunnels (cross-sectional area $\mathrm{A}=$ $5.58 \mathrm{~m}^{2}$ ), otherwise $A=22.3 \mathrm{~m}^{2}$

- The peak pressure beyond $3 \mathrm{~m}$ is nearly independent of the initial bomb configuration. 
- Our calculations of the Norway tunnels predict a transition from a blowout to spall at a standoff distance between 3.7 and $7.0 \mathrm{~m}$.

- For a small $2.5 \mathrm{~m}$ diameter tunnel, we predict $12 \%$ less rubble at 2.8 $\mathrm{m}$ standoff, $25 \%$ less rubble at $3.7 \mathrm{~m}$, and $44 \%$ less rubble at $7.0 \mathrm{~m}$.

- Shear strength, water saturation, air filled porosity, and tensile strength are the main rock parameters that determine the amount of rubble.

- Feedback from the experimental results is crucial for development and refinement of calculational models

\section{Comments and recommendations}

When all the results of the experimental program are collected and described in a report, the field data may be used to refine our constitutive models and failure criteria. With a calibrated model, it is then straight forward to predict with a high degree of confidence what would happen in larger tunnels at various standoff distances.

All the calculations described in this report were done using a 2-D code. While a great deal of insight may be gained from these calculations, they are inherently limited to a single charge and cannot predict the amount of rubble in a portal attack. In order to calculate the effect of multiple charges or predict the damage in more complicated geometries, a 3-D code is generally required.

As a follow up on this work we recommend the following:

- Redo some of the tunnel calculations in 3-D and compare predictions with the available data to improve the predictive capability.

- 3-D calculations of multiple charges to determine the effect of number of charges and charge separations on peak pressure and impulse on target in real geologies.

- Investigate the effect of various rock material properties on the amount of rubble and develop calibrated constitutive and failure models for a variety of rocks. 


\section{Acknowledgments}

The authors would like to acknowledge the various discussions with Lew Glenn, Janet Jones-Oliveira, Robert Managan, Michael Schwab, and Robert Tipton from Lawrence Livermore National Laboratory. The asbuild standoff distances and tunnel configurations were provided by Robert Welch and Will McMahon from the U.S. Army Engineer Waterways Experiment Station. Funding for this work was provided by Steve Korn at the Munitions Division of the Armament directorate at Eglin Air Force Base. The principal investigators of the experimental program were Al Weimort at Eglin Air Force Base and Paul Senseny at Defense Nuclear Agency.

\section{References}

1- Tipton, R. E., "A 2D Lagrange MHD Code," Proceedings of the Fourth International Conference on Megagaus Magnetic Field Generation and Related Topics, C. M. Fowler, R. S. Caird, and D. J. Erickson, eds., (Plenum Press, New York, 1987) pp. 299.

2- McGlaun, J. M., S. L. Thompson, L. N. Kmetyk, M. G. Elrick, "A Brief Description of the Three-Dimensional Shock Wave Physics Code CTH", Sandia Report SAND89-0607 (1990).

3- Johnson, G. R., R. A. Stryk, E. H. Petersen, T. J. Holmquist, J. A. Schonhardt, and C. R. Burns, User Instructions for the 1995 Version of the EPIC Code, Alliant Techsystems, Nov. 1994.

4- Couch, R., R. Sharp, I. Otero, R. Tipton, and R. McCallen, "Application of ALE techniques to metal forming simulations," AMD-Vol 180, Advanced Computational Methods for Material Modeling, Editors: D. J. Benson, and R. J. Asaro, Book No H00883 - 1993.

5- Burton, D. E., "Consistent Finite-Volume Discretization of Hydrodynamic Conservation Laws for Unstructured Grids," Eighth Nuclear Explosives Code Developers Conference (NECDC), Las Vegas NV, UCRL-JC 118788, October 1994.

6- Killian, B., S. Schuster, V. Koik, J. Rocco, G Lloyd, and L. Germain, "An Examination of Velocity Fields in Cratering Events" CRT report CRTATR-5690-1 under contract \#9-X65-X4126-1, February 1986. 
7- Butkovich, T. R., "Effect of Water Saturation on Underground Nuclear Detonation," Lawrence Livermore National Laboratory, Rept. UCRL-5110 (1971).

8- Broch, E. "The influence of water on some rock properties," In Advances in Rock Mechanics, Proc. 3rd Congr., Intnl. Soc. Rock Mech., Denver. 1974, Vol 2 Part A pages 33-38.

9- Boadu, F. K. and L. T. Long "The Fractal Character of Fracture Spacing and RQD," Int. J. Rock Mech. Min Sci \& Geomech. Abstr. Vol. 31 No 2, pp. 127-134, 1994 
The hydrocode solves the dynamic equations of motion subject to the materials response and conservation of mass and energy

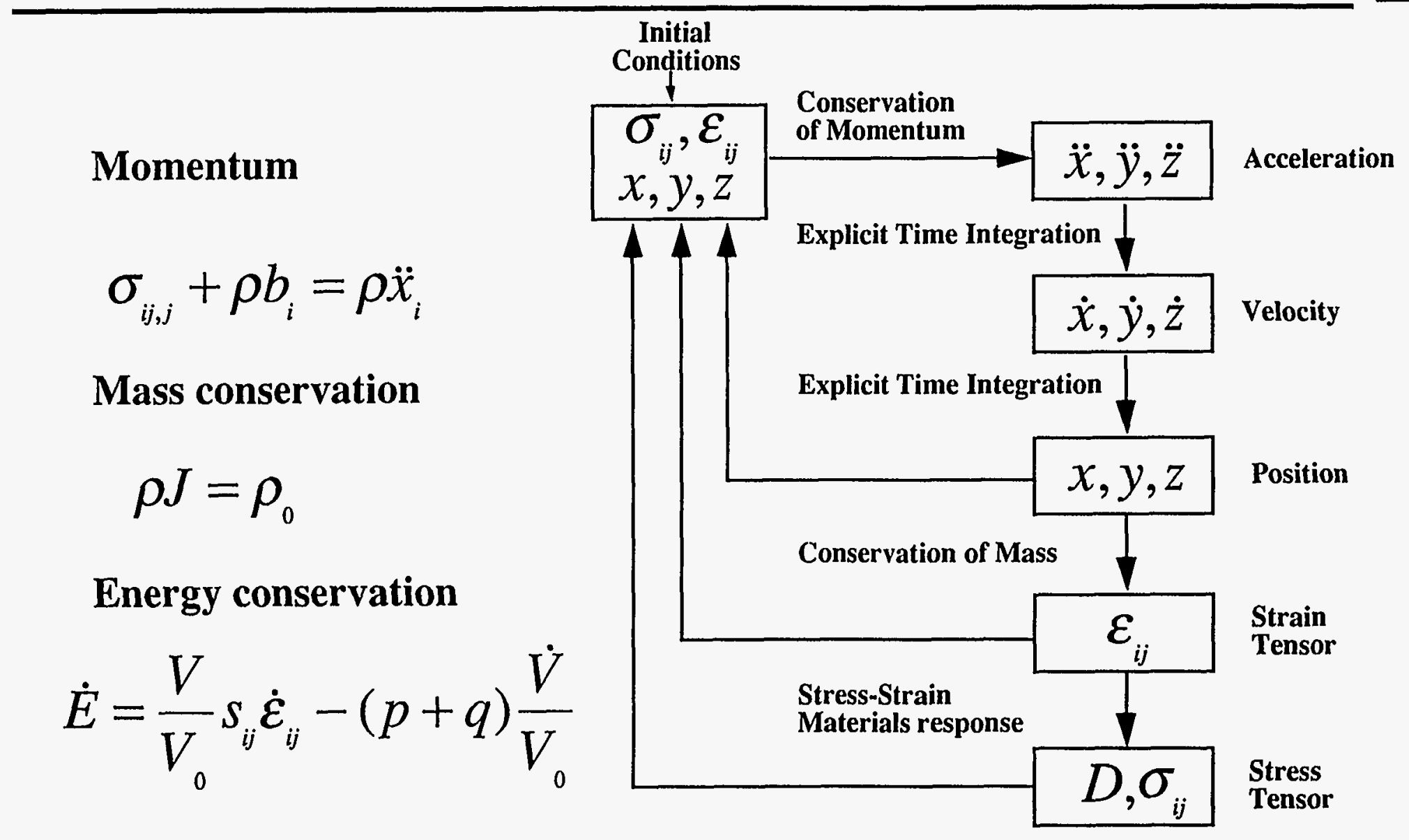

Calculate until amount of damaged rock stabilizes in time

Slide 1: Flowchart of a hydrocode 


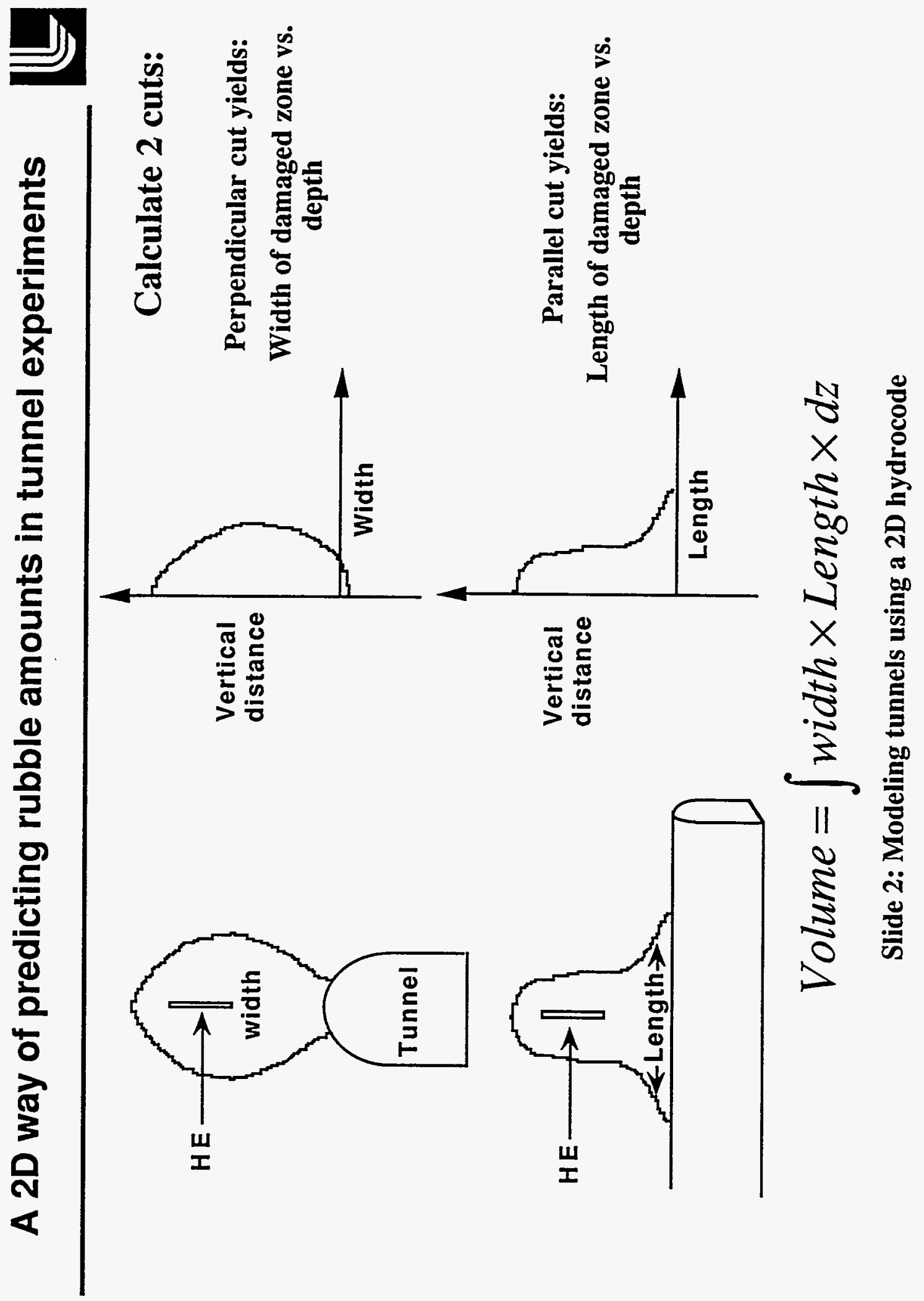




\section{For very large* tunnels, the error from 2-D modeling is small}
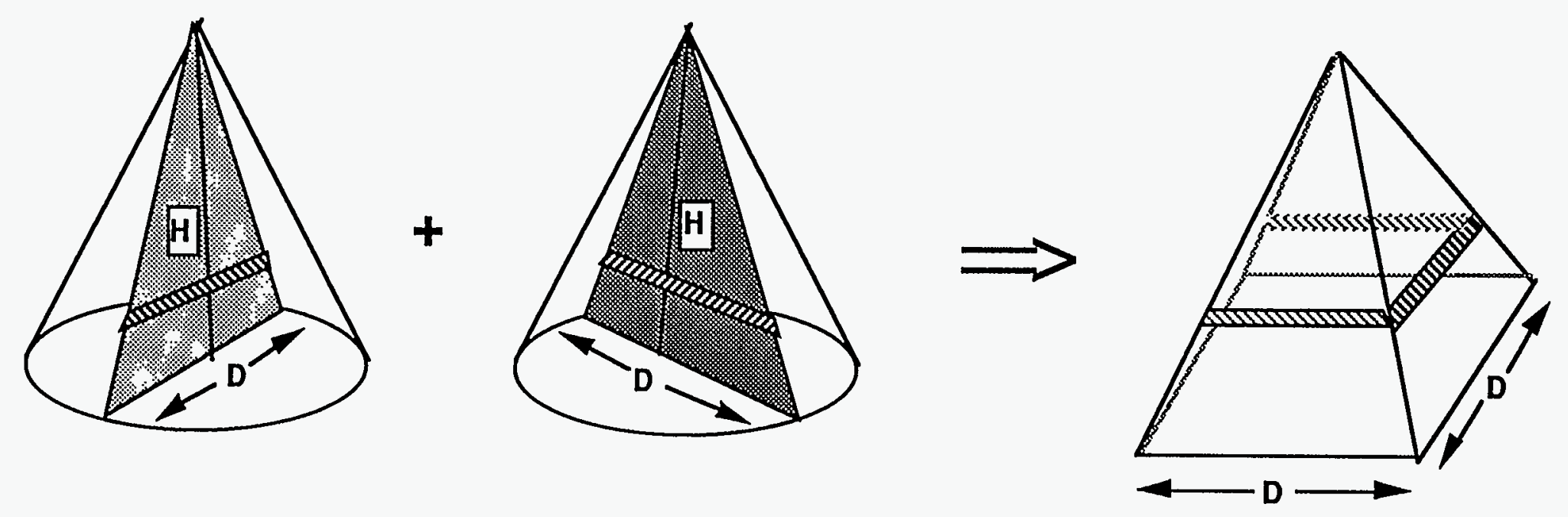

$$
\frac{\text { Volume }_{2 D}}{\text { Volume }_{3 D}}=\frac{1 / 3 D^{2} H}{1 / 12 \pi D^{2} H} \cong 1.27
$$

* Large relative to standoff distance 


\section{Rock constitutive model for tunnel calculations}

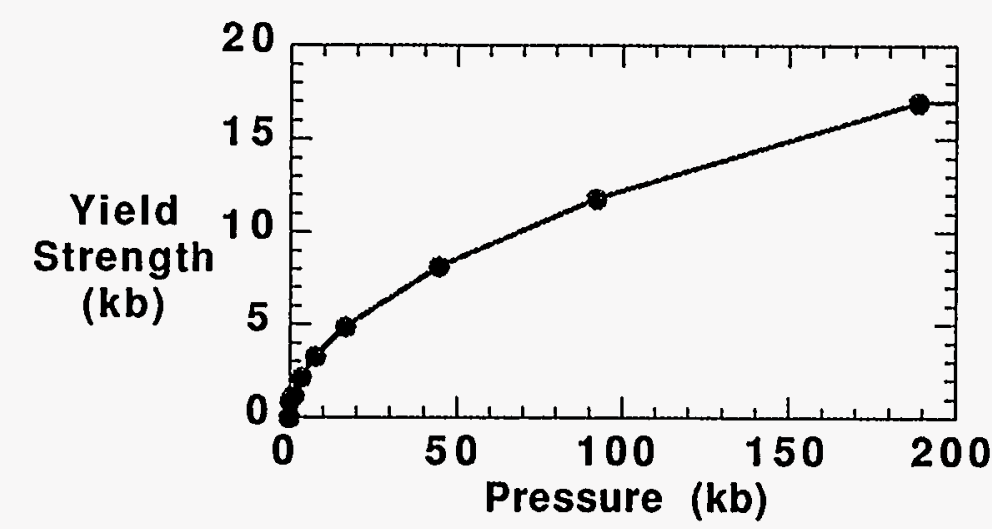

Bulk modulus $=200 \mathrm{~kb}$

Poisson's ratio $=0.25$

Air filled porosity $=0$

Damage calculations:

$$
f=\left(\frac{e^{p}}{e_{\max }^{p}}\right)^{2}+\left(\frac{\sigma_{1}}{\sigma_{1 \max }}\right)^{2}
$$

Equivalent plastic strain $=5 \%$

$$
\text { If } f(>1) \quad \dot{D}=0.5 * u / \Delta x
$$

Maximum tensile stress $=100$ bars $^{*}$

$$
\text { else } \quad \dot{D}=0
$$

*For Westerly granite Glenn and Janach measured 83 bars using the pinch test and 114 bars using the Brazilian test 


\section{Norway tunnels: Characteristics and implications}

Characteristics:

- The rock around the tunnels was water saturated

- Reduction in shear strength

Physical basis: Decreased $J$ and $\beta$

- Reduction in fracture toughness $\mathbf{d} \alpha \mathbf{K}^{2 / 3}$

- Mitigation of joint spacing and orientation

$\Psi \cong 0$

- The diameter of the tunnels was comparable to or larger than the standoff distances

- Importance of free surface

Implications:

- Larger rubble volumes predicted from Norway

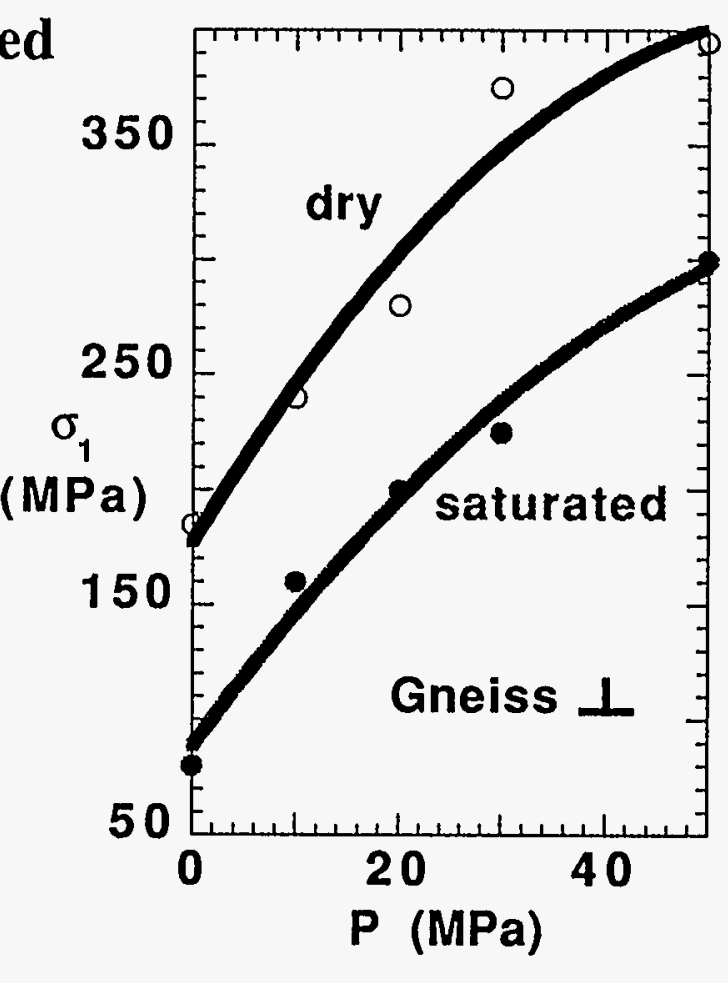
tunnels compared with smaller tunnels in dry rock.

(Data in the graph is from E. Broch, Norwegian Institute of Technology, Trondheim, Norway)

Slide 5: Characteristics and implications of the Norway tunnels 
The initial bomb configuration can be modeled as a spherical source
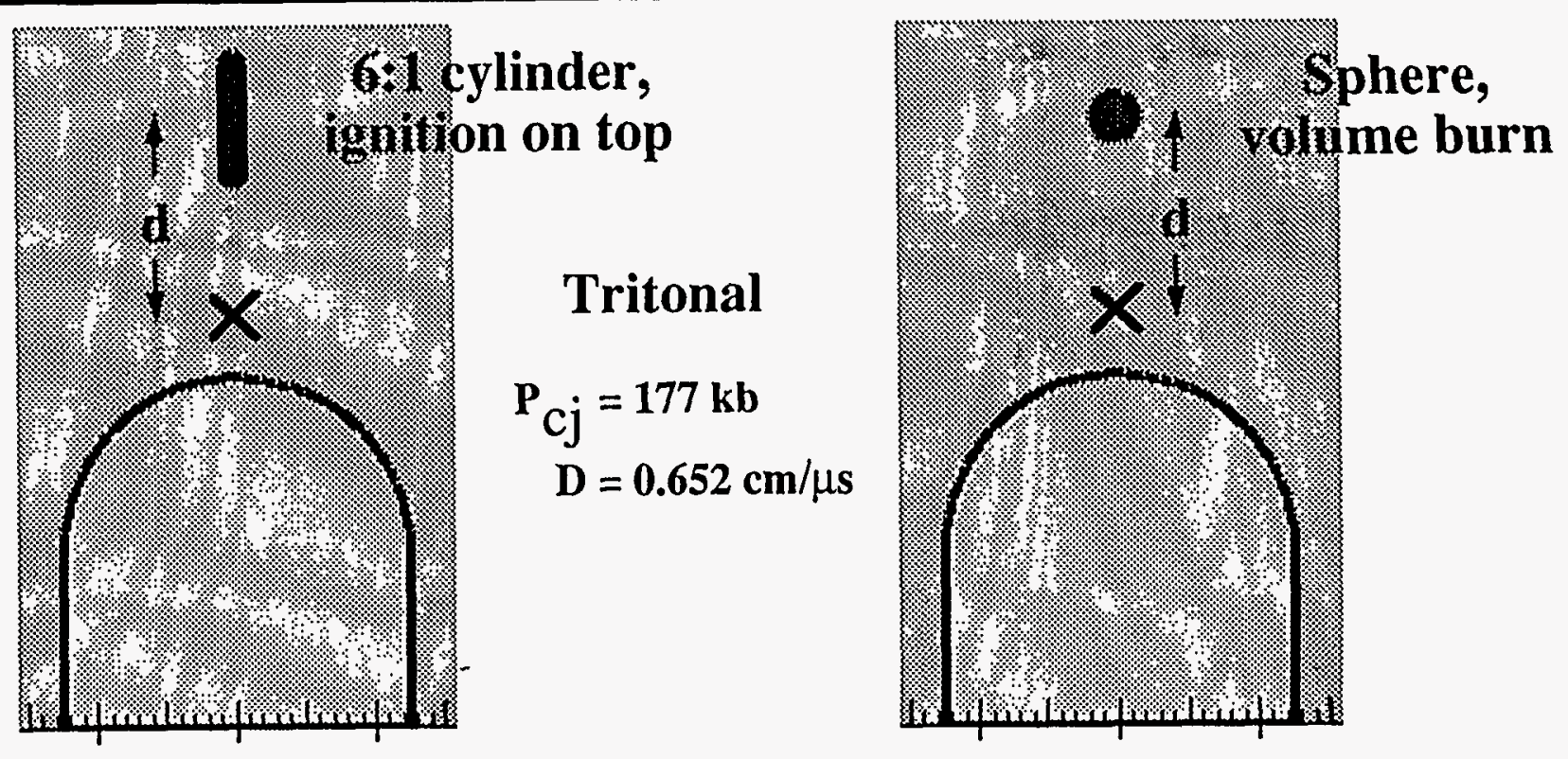

- Why do it? (Numerical and practical reasons)

- How does peak pressure at a given distance d, differ in the two cases?

- How does rubble volume differ in the two cases?

Slide 6: modeling the initial bomb configuration 
Highest peak pressure is ahead of the bomb nose

$\begin{aligned} \text { Largest pressure } & =15 \mathrm{~kb} \\ \text { Front location } & =1.3 \mathrm{~m} \\ \text { Pressure at front } & =15 \mathrm{~kb}\end{aligned}$

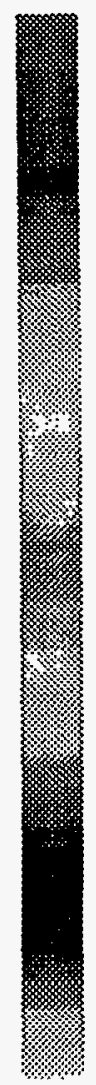

Largest pressure $=8 \mathrm{~kb}$

Front location $=1.5 \mathrm{~m}$

Pressure at front $=4 \mathrm{~kb}$

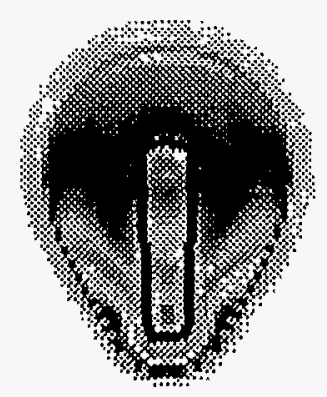

6:1 cylinder, ignition on top

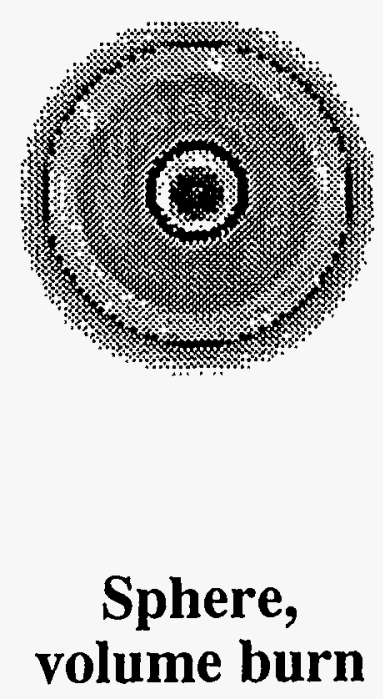

Slide 7: Pressure contours at $0.4 \mathrm{~ms}$ 
Initial shock front depends on bomb aspect ratio and ignition point

Largest pressure $=3.6 \mathrm{~kb}$

Front location $=2.5 \mathrm{~m}$

Pressure at front $=2.0 \mathrm{~kb}$

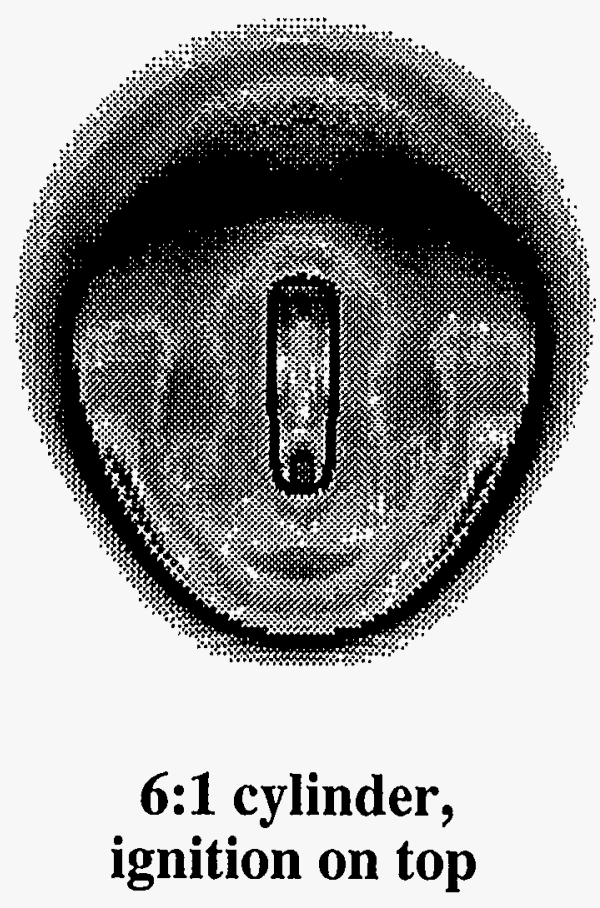

Largest pressure $=2.8 \mathrm{~kb}$

Front location $=2.7 \mathrm{~m}$

Pressure at front $=1.6 \mathrm{~kb}$

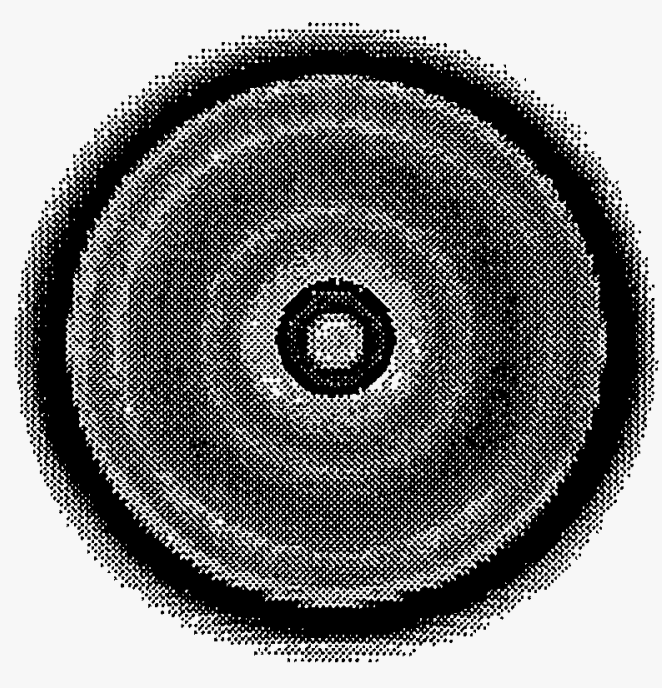

Sphere, volume burn

Slide 8: Pressure contours at $0.8 \mathrm{~ms}$ 
The shock front from the bomb rapidly spherizes

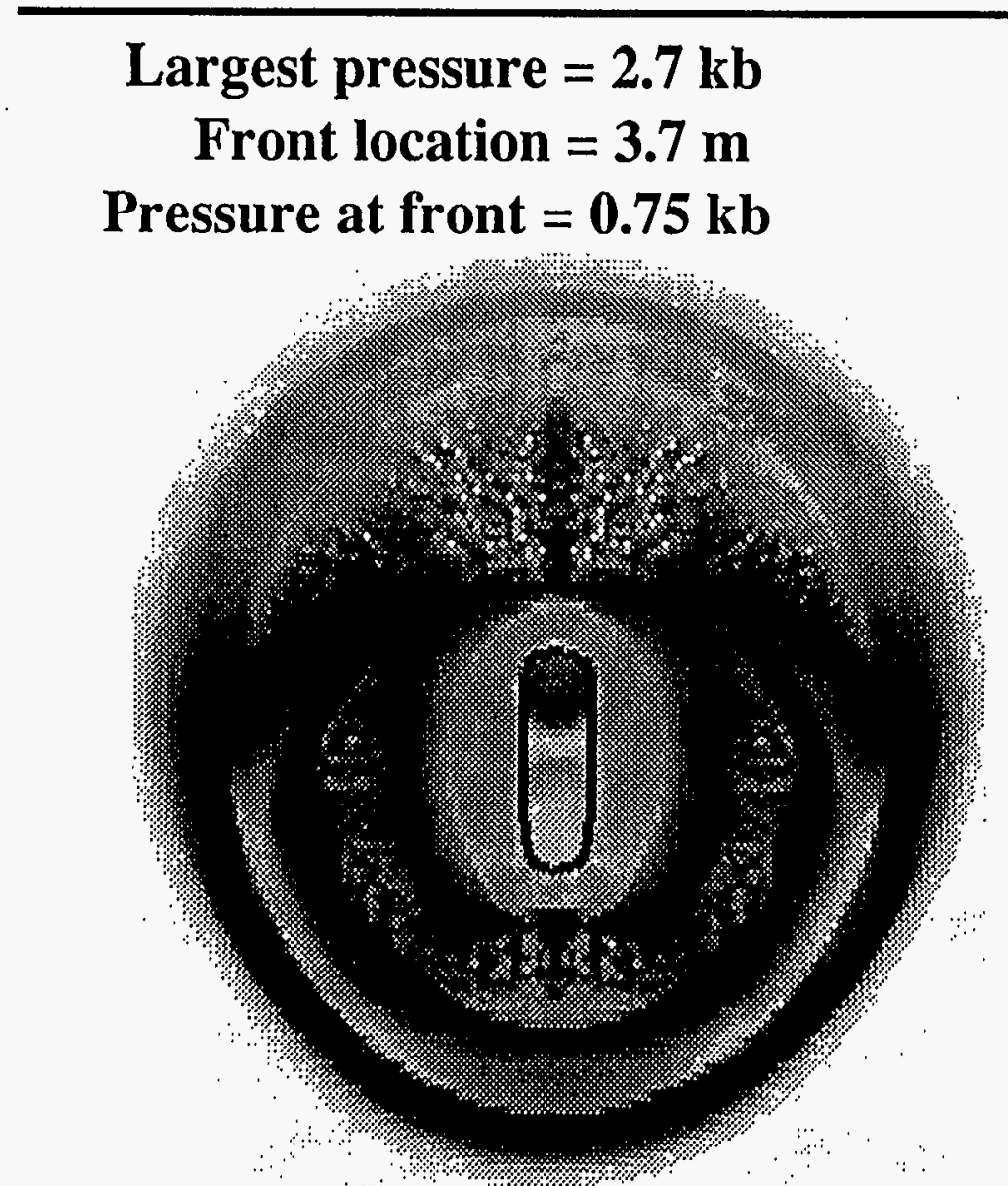

6:1 cylinder, ignition on top

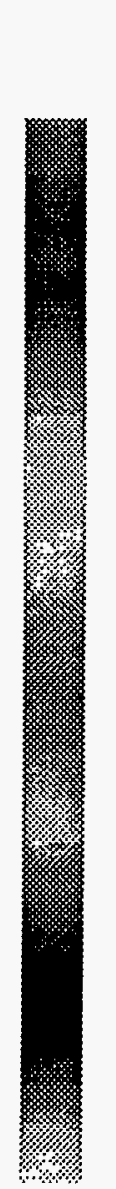

Largest pressure $=\mathbf{2 . 2} \mathrm{kb}$

Front location $=3.9 \mathrm{~m}$

Pressure at front $=0.64 \mathrm{~kb}$

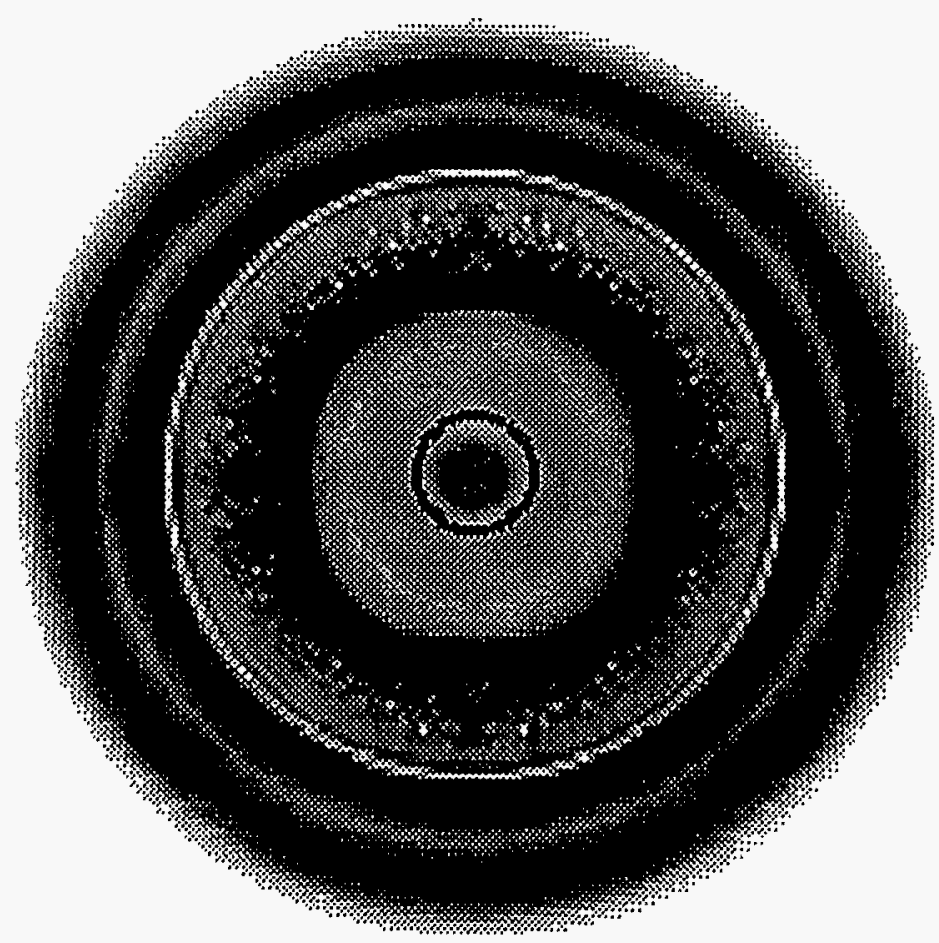

Sphere, volume burn 
The front is nearly spherical at a distance equal to 3 times the length of the bomb

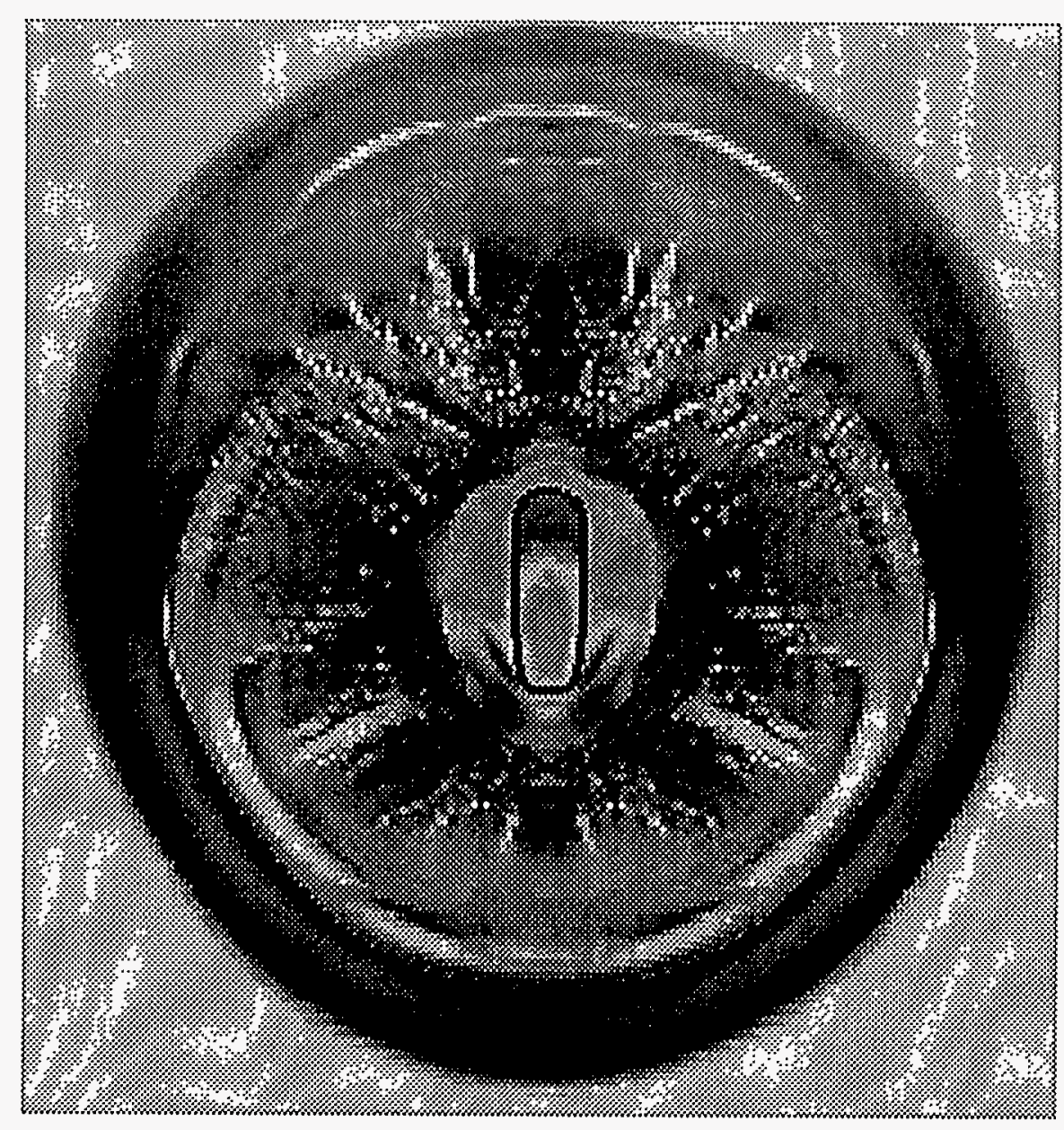

\section{Bomb:}

Largest pressure $=2.2 \mathrm{~kb}$

Front location $=5.1 \mathrm{~m}$

Pressure at front $=0.4 \mathrm{~kb}$

\section{Sphere:}

Largest pressure $=1.7 \mathrm{~kb}$

Front location $=5.4 \mathrm{~m}$

Pressure at front $=0.4 \mathrm{~kb}$

Slide 10: Pressure contours at $1.6 \mathrm{~ms}$ 
Peak pressure beyond $3 \mathrm{~m}$ is nearly independent of initial configuration

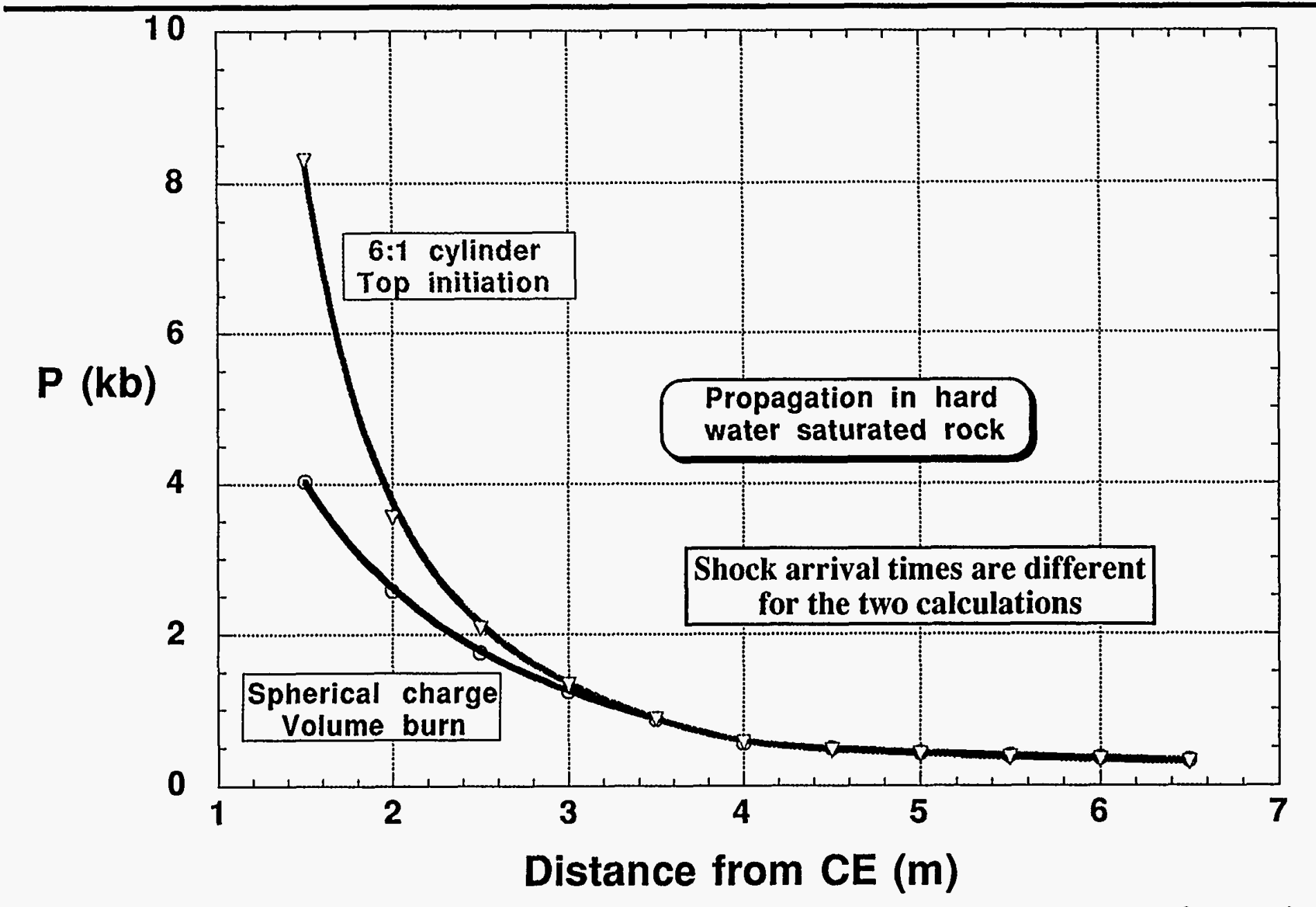

Slide 11: Dependence of peak pressure on distance from center of explosive 
Final volume of damaged rock is nearly independent of initial explosive configuration

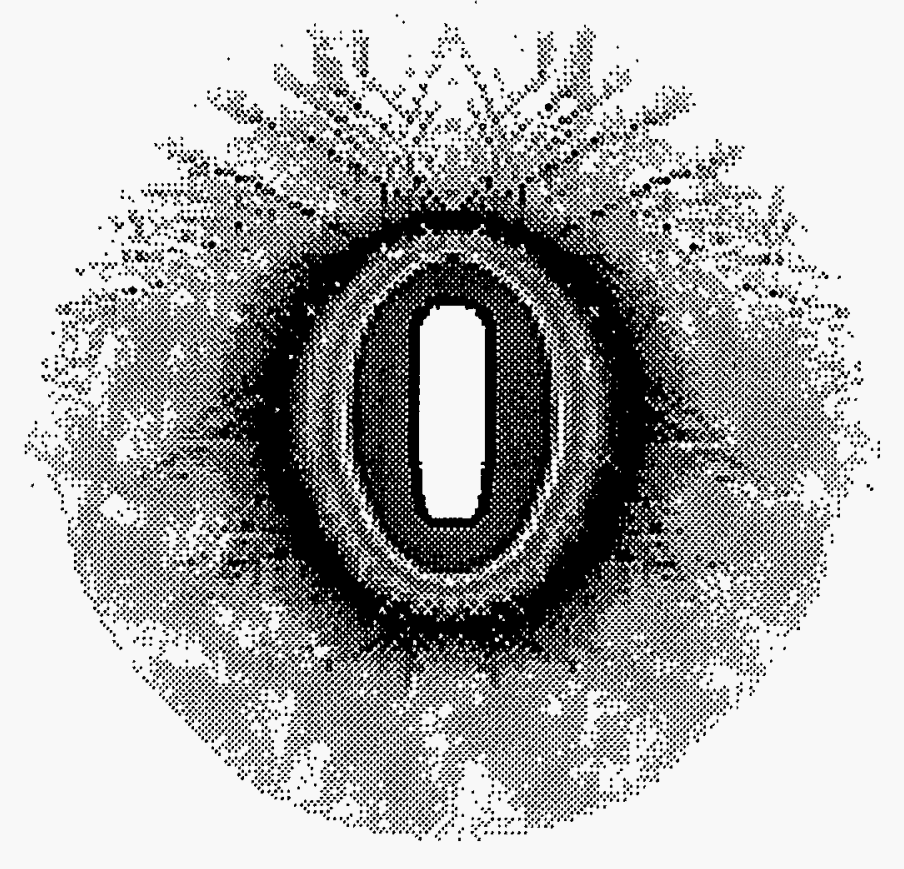

6:1 cylinder, ignition on top

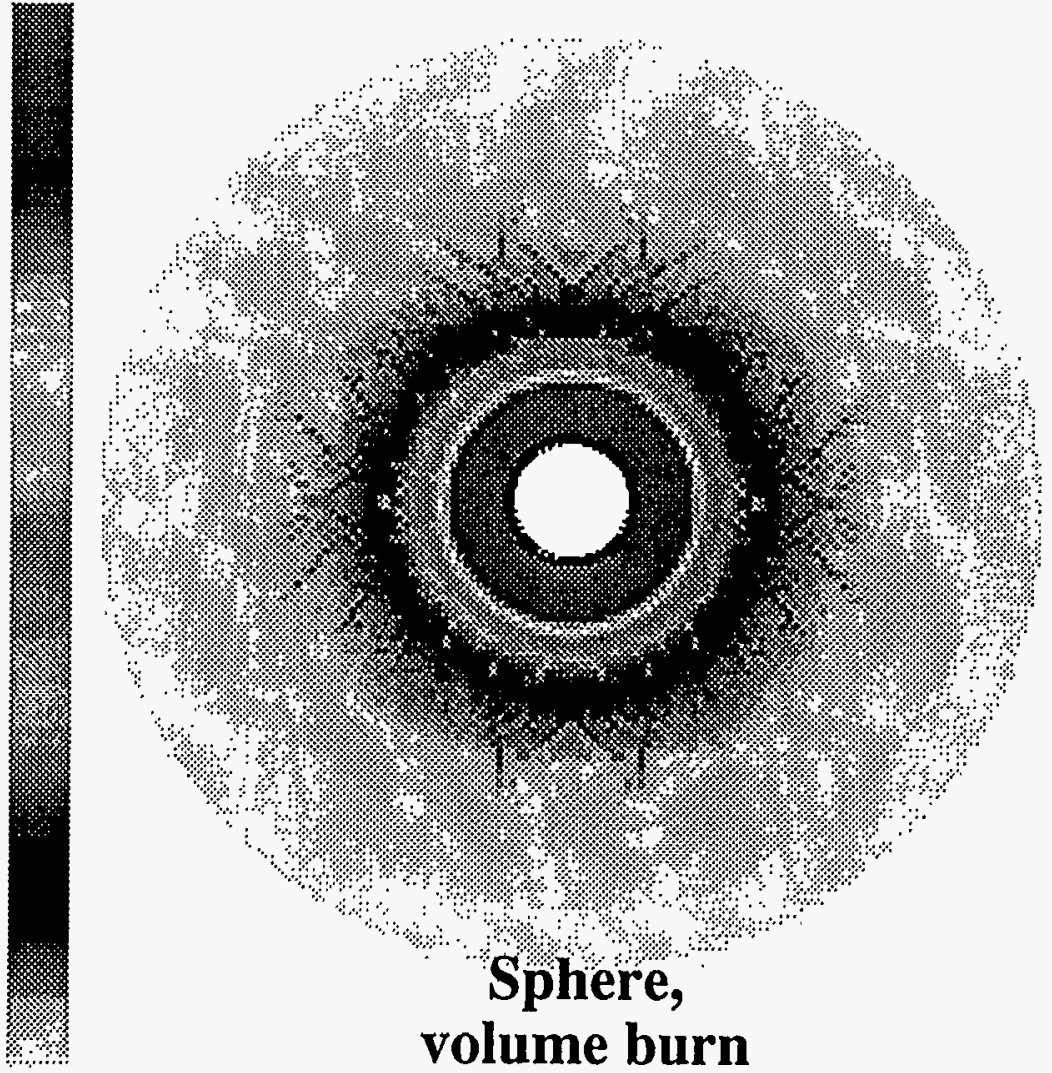

Slide 12: Plastic strain contours at time $=1.6 \mathrm{~ms}$ 
The calculated transition between blowout and spall occurs at a standoff distance between 3.7 and $7 \mathrm{~m}$

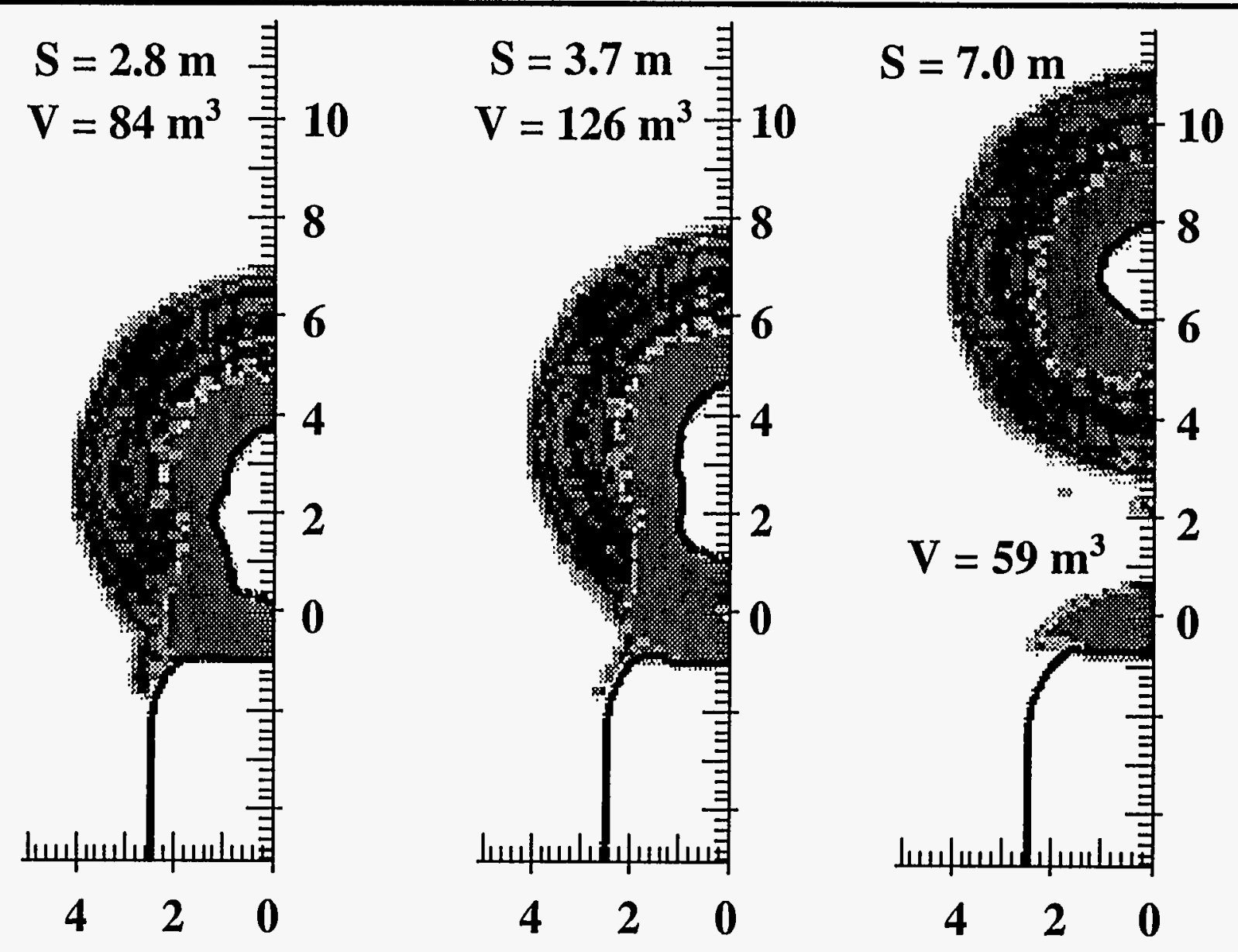

Slide 13: Damage contours for the 3 adit experiments 


\section{At $2.8 \mathrm{~m}$ standoff, calculations show that a very strong shock reaches the tunnel roof}

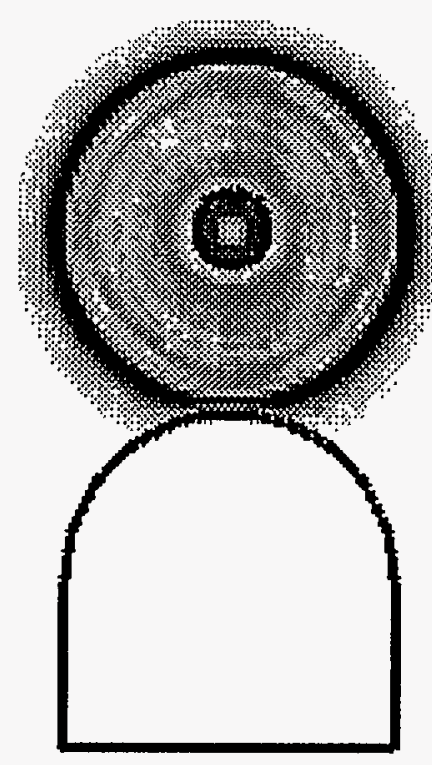

$0.7 \mathrm{~ms}$

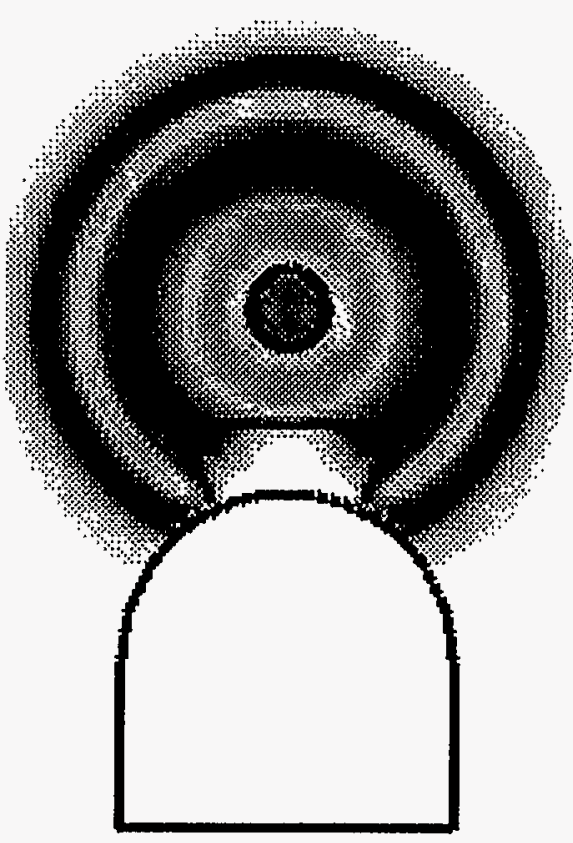

$1.0 \mathrm{~ms}$

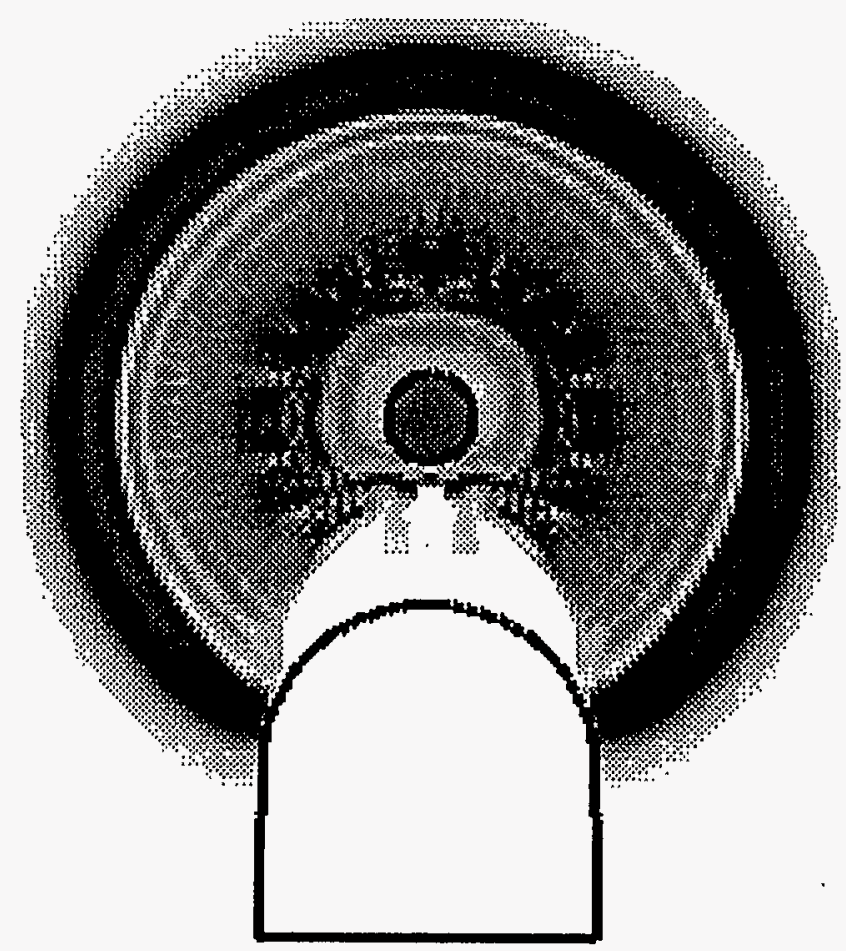

$1.5 \mathrm{~ms}$

Slide 14: Pressure contours showing reflected tensile wave 
Calculated cross section for a $\mathbf{2 . 8} \mathrm{m}$ standoff indicates early link up of shear- and tension-failed zones

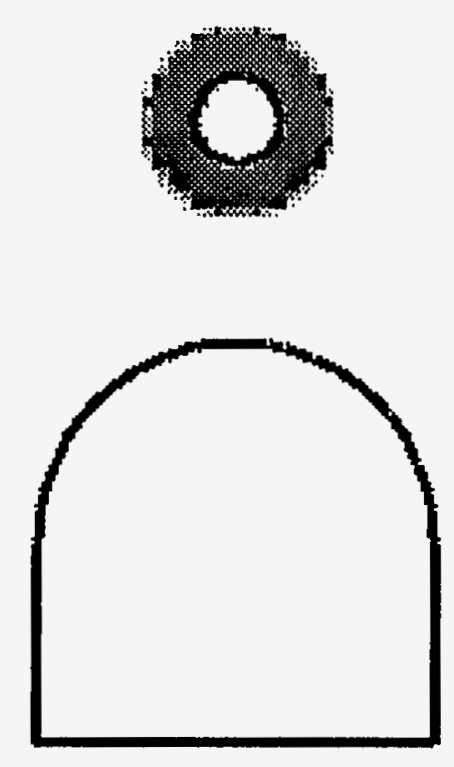

$0.7 \mathrm{~ms}$

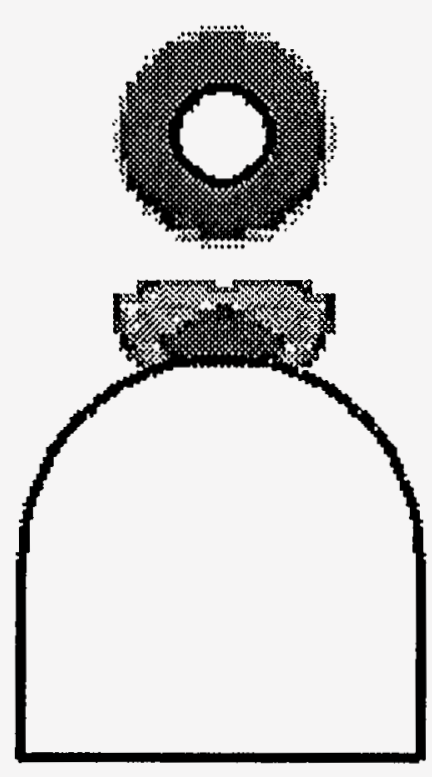

$1.0 \mathrm{~ms}$

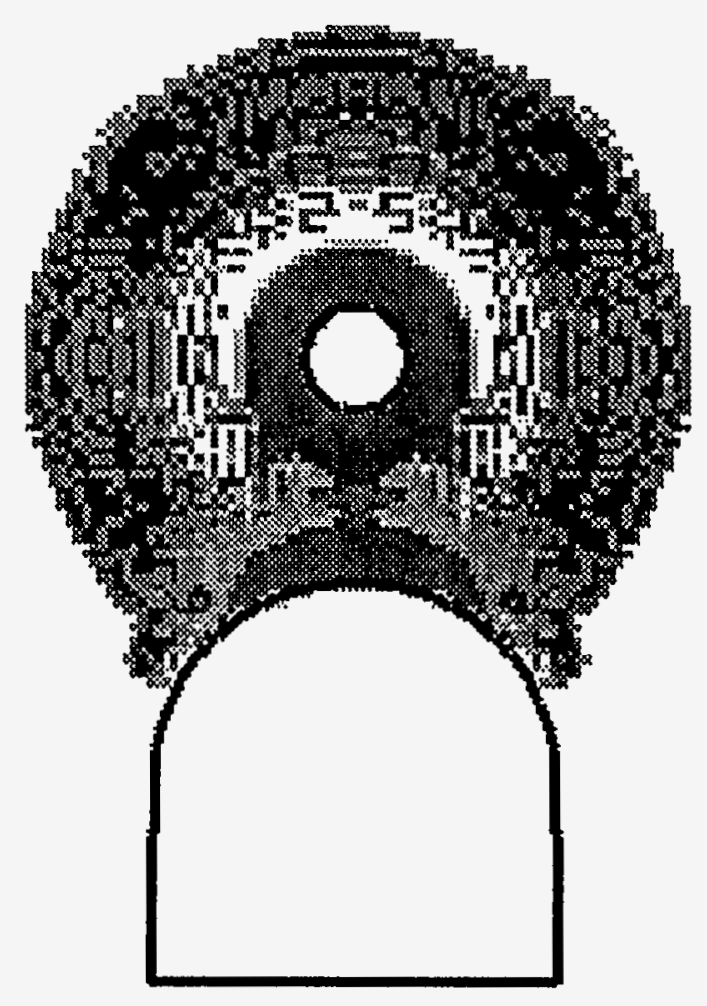

$1.5 \mathrm{~ms}$

Slide 15: Calculated damage progression at 3 different times for the $2.8 \mathrm{~m}$ standoff 


\section{The calculated amount of damaged rock reaches an asymptotic value (Standoff $=2.8 \mathrm{~m}$ )}

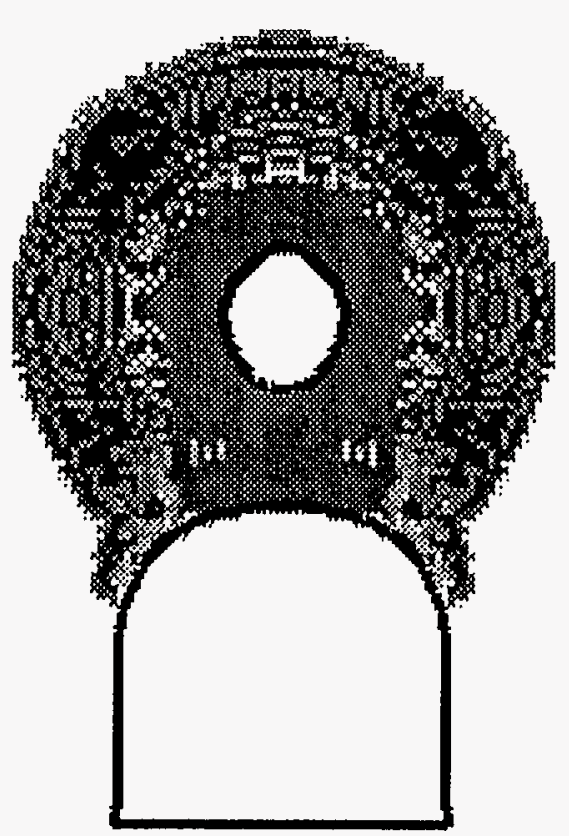

$7 \mathrm{~ms}$

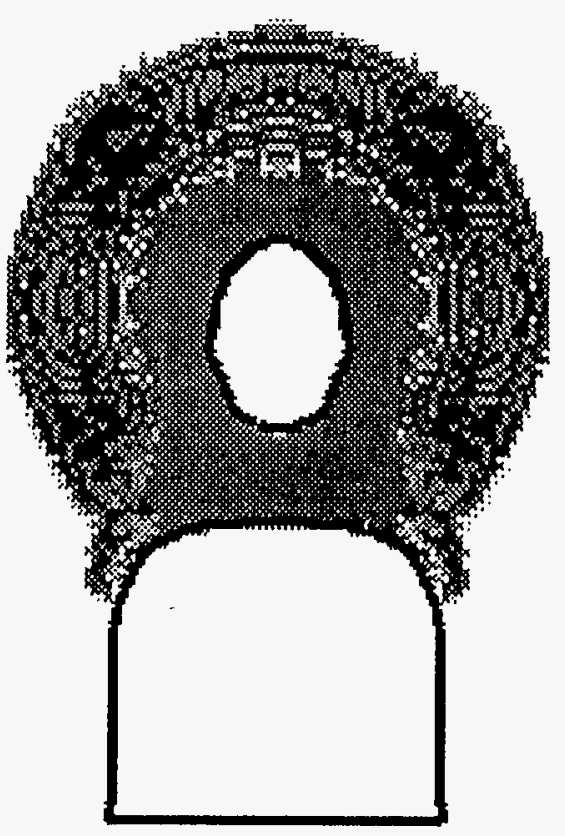

$14 \mathrm{~ms}$

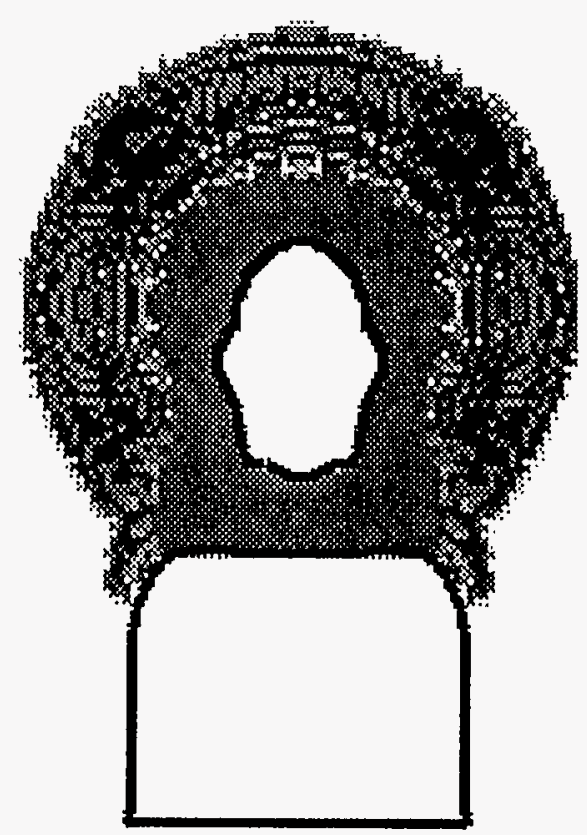

$21 \mathrm{~ms}$

Slide 16: Damage contours perpendicular to the tunnel 


\section{The calculated amount of damaged rock reaches an asymptotic value (Standoff $=2.8 \mathrm{~m}$ )}
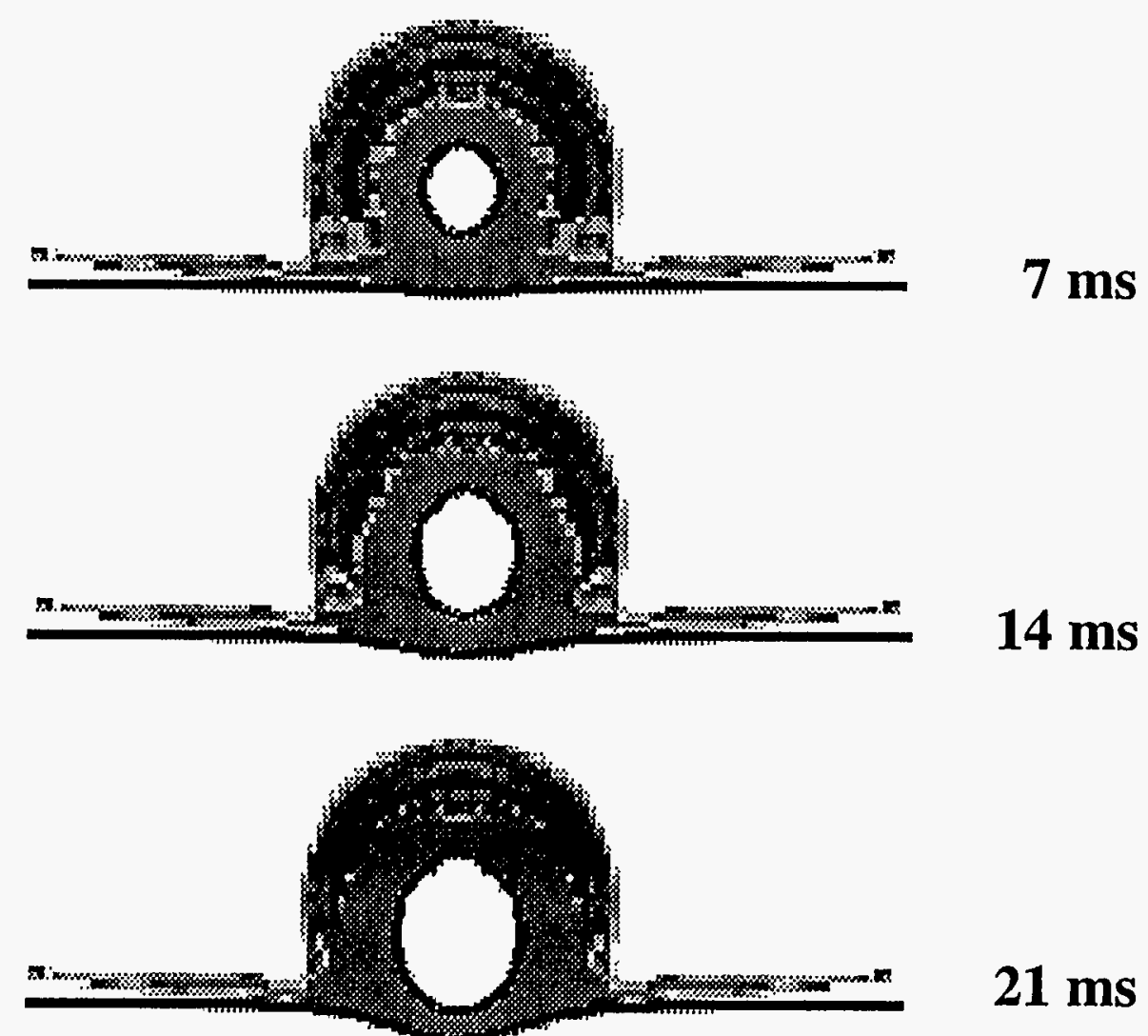

Slide 17: Damage contours parallel to the tunnel 


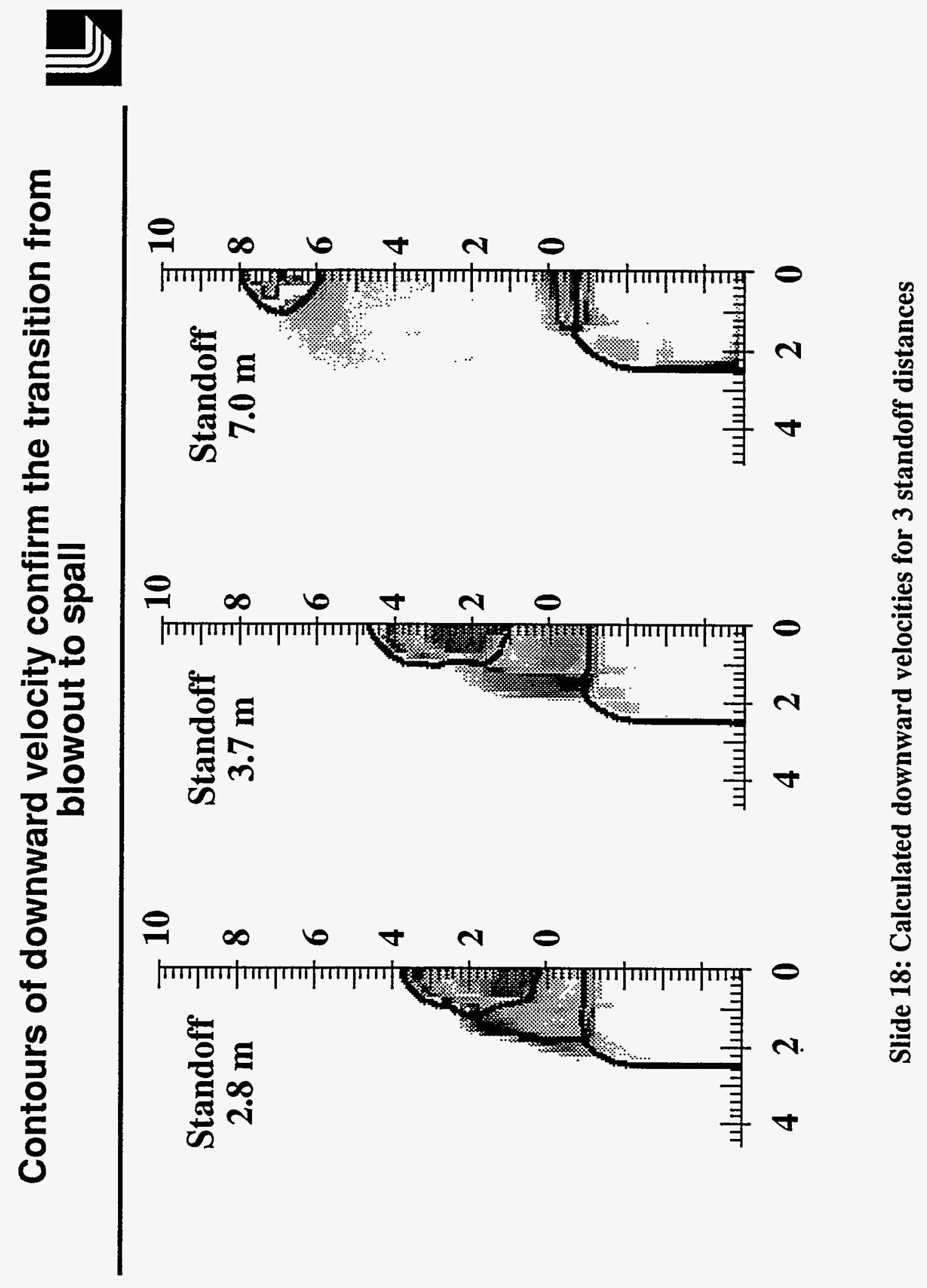


Calculated fractured rock at a $2.8 \mathrm{~m}$ standoff indicate a blowout crater for both the small and large tunnels

Small tunnel, $A=5.58 \mathrm{~m}^{2}$

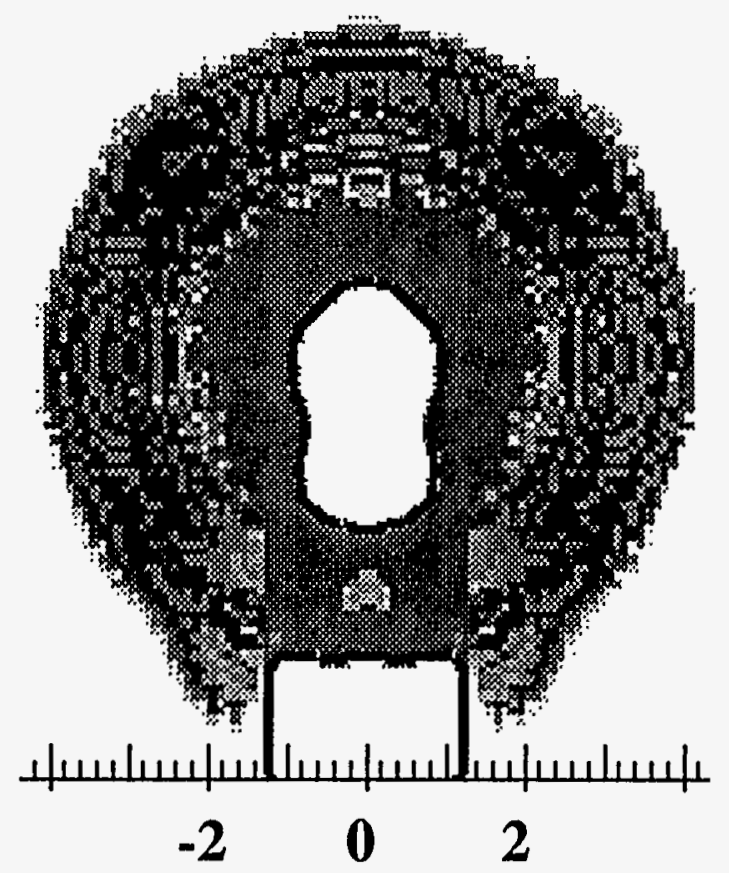

$$
\mathrm{V}=74 \mathrm{~m}^{3}
$$

Large tunnel, $A=22.3 \mathrm{~m}^{2}$

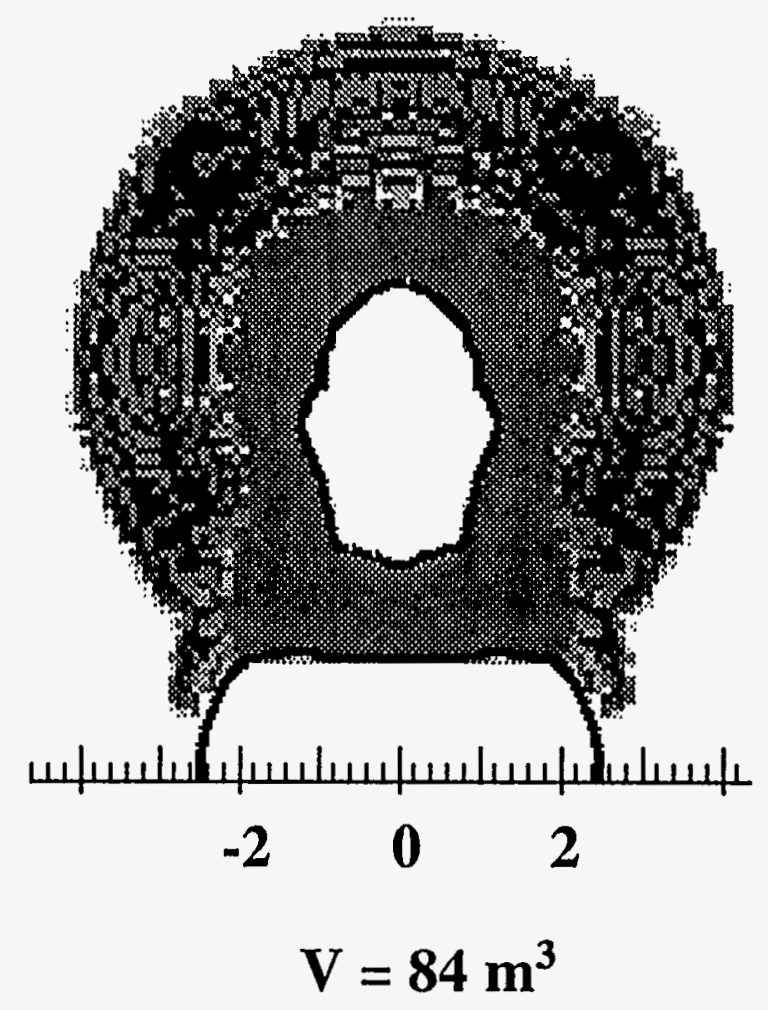

Slide 19: Damage contours at a $2.8 \mathrm{~m}$ standoff for a small and a large tunnel 
Calculated fractured rock at a $3.7 \mathrm{~m}$ standoff indicate a near transition for the small tunnel and a blowout crater for the large tunnel

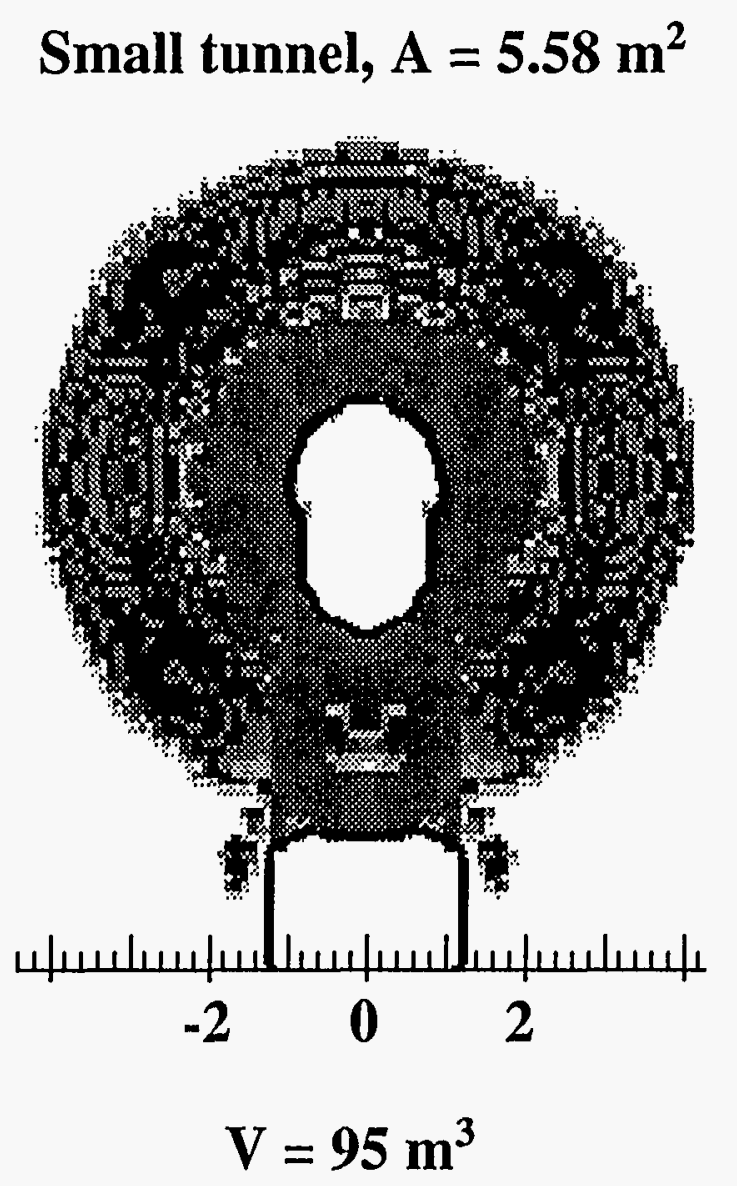

Large tunnel, $A=22.3 \mathrm{~m}^{2}$

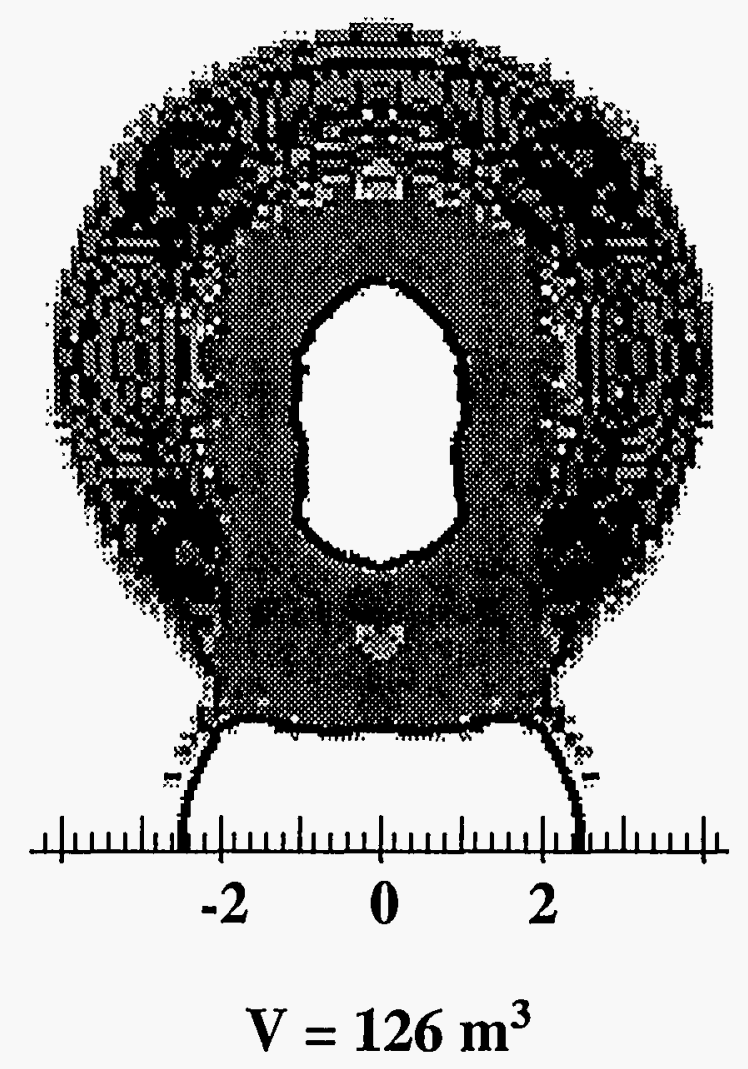

Slide 20: Damage contours at a $3.7 \mathrm{~m}$ standoff for a small and a large tunnel 
Calculated fractured rock at a $7.0 \mathrm{~m}$ standoff indicate a spall crater for both the small and large tunnels

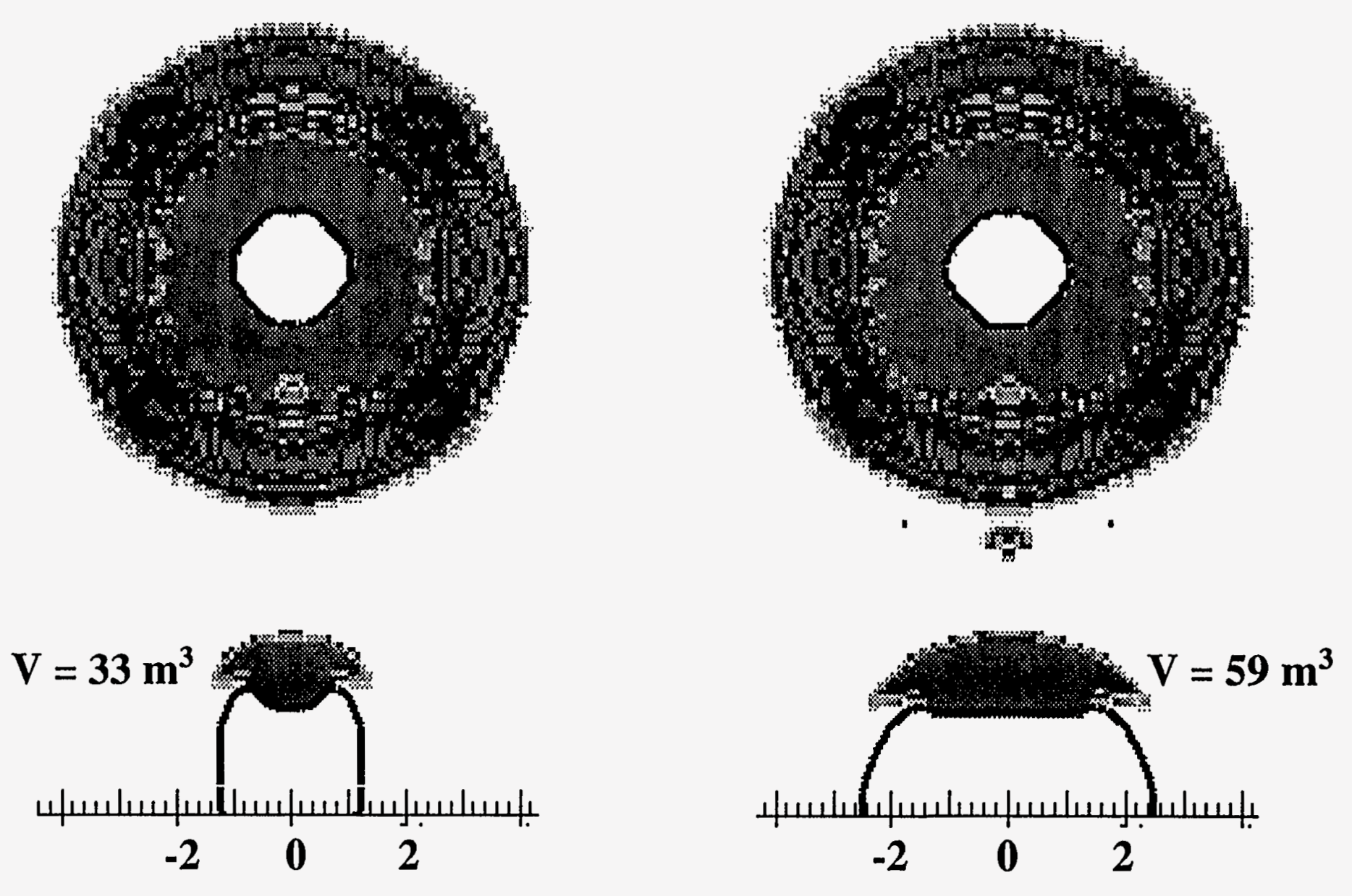

Slide 21: Damage contours at a $7.0 \mathrm{~m}$ standoff for a small and a large tunnel 
Calculated crater depth is nearly independent of the tunnel cross section $\mathbf{A}$, but rubble volume at large standoff scales with $\sqrt{\mathbf{A}}$
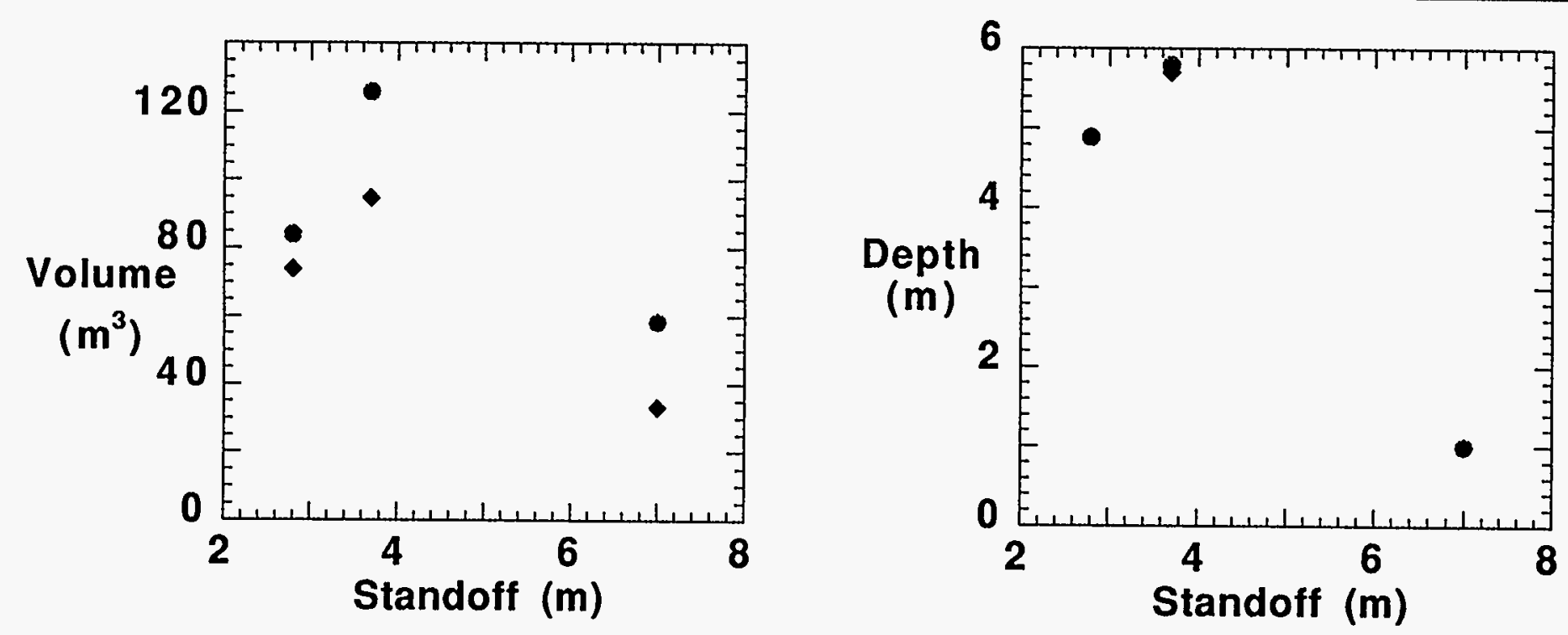

- Norwegian tunnels $\left(A=22.3 \mathrm{~m}^{2}\right)$

- Small tunnels $\left(A=5.58 \mathrm{~m}^{2}\right)$

Slide 22: Calculated rubble volumes and crater depths in water saturated hard rock 